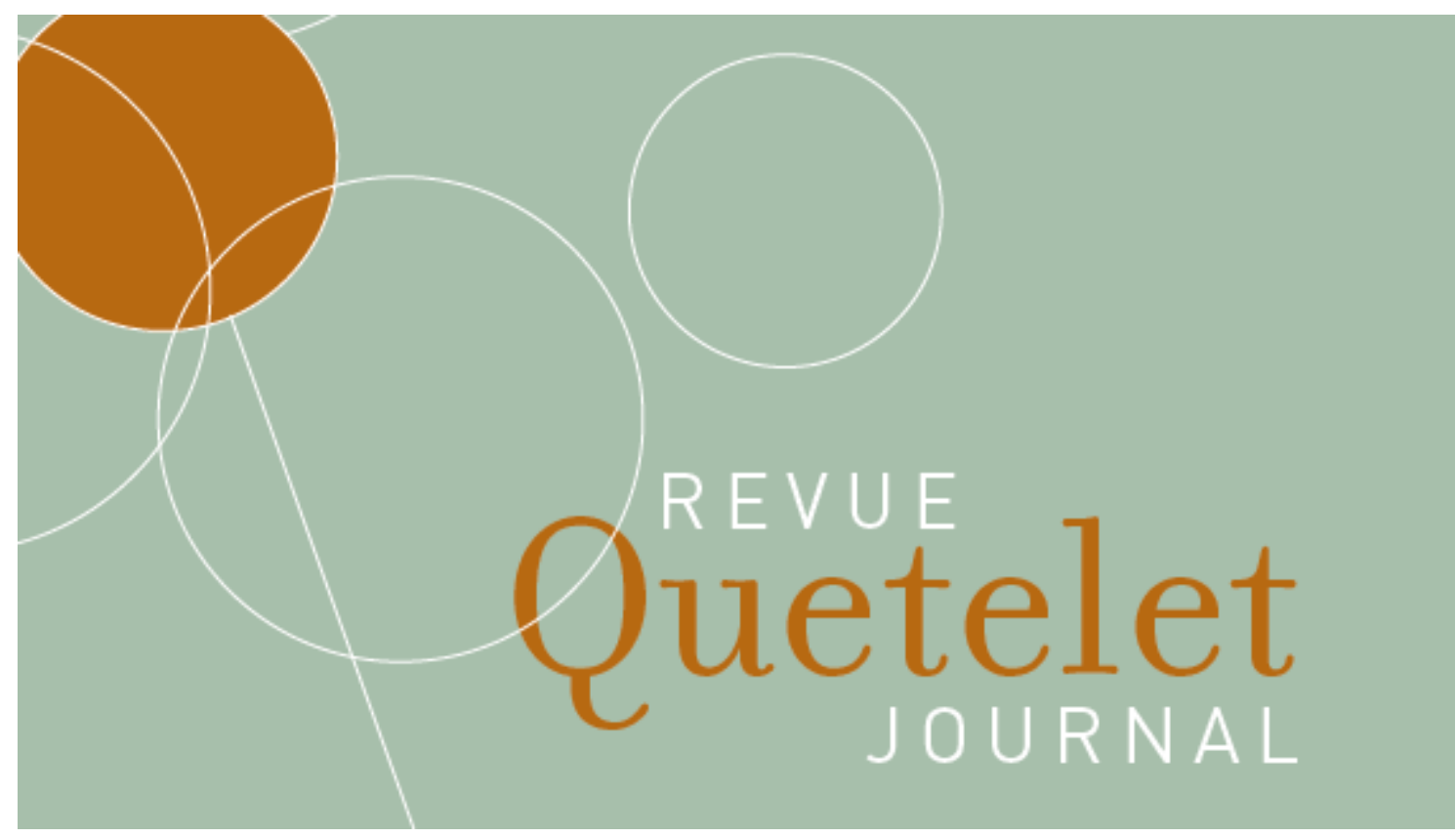

Vol. 8, $\mathrm{n}^{\circ} 2$, 2020, pp. 7-59

DOI : 10.14428/rqj2020.08.02.01

ISSN: 2593-9157

\title{
Mortality in Belgium from nineteenth century to today
}

Variations according to age, sex, and social and spatial contexts

Thierry Eggerickx, Jean-Paul Sanderson, Christophe Vandeschrick

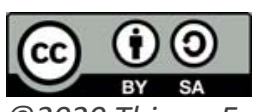

(C)2020 Thierry Eggerickx, Jean-Paul Sanderson, Christophe Vandeschrick

This work is licensed under a Creative Commons Attribution-NonCommercial 4.0 International License. You can share, adapt the material for non-commercial purposes provided that you give appropriate credit and indicate if changes were made. For details see https://creativecommons.org/licenses/by-sa/4.0/

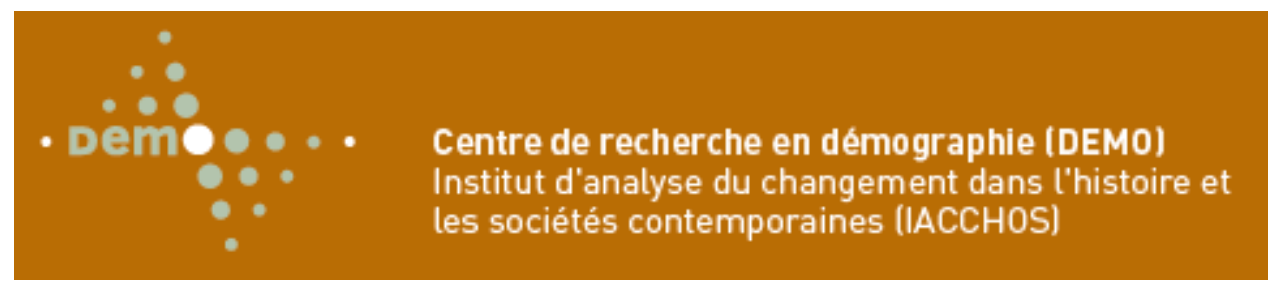





\title{
Mortality in Belgium from nineteenth century to today \\ Variations according to age, sex, and social and spatial contexts
}

\author{
THIERRY EGGERICKX \\ JEAN-PAUL SANDERSON \\ CHRISTOPHE VANDESCHRICK ${ }^{1}$
}

\begin{abstract}
Résumé
Cet article dresse une synthèse de l'évolution de la mortalité en Belgique du 19ème siècle à nos jours en mettant l'accent sur les inégalités socio-démographiques et spatiales. Il se base sur une revue de la littérature et exploite les données de la Human Mortality Database (HMD) pour les analyses consacrées à l'évolution de la mortalité selon l'âge et le sexe depuis le début du 19ème siècle. L'appariement des données du Registre national, des recensements de la population et des bulletins de décès de l'état-civil est mobilisé pour les analyses plus récentes (1991-2015).

En Belgique, la durée moyenne de vie dépasse aujourd'hui 80 ans, soit deux fois plus qu'il y a 170 ans. Mais, comme dans d'autres pays occidentaux, des inégalités subsistent et parfois même se renforcent. Ainsi, les inégalités entre groupes sociaux face à la mort sont importantes et elles se sont accentuées depuis le début des années 1990, au moins. Ces différences sociales s'observent pour toutes les causes de décès et à tous les âges, chez les femmes comme chez les hommes. Les disparités spatiales de mortalité, à l'échelle des régions, des arrondissements et des milieux de résidence se sont également accrues depuis au moins un quart de siècle. De plus, à même groupe social, les disparités spatiales de mortalité persistent. Cela signifie que des facteurs environnementaux, culturels, comportementaux agissent de la même manière sur la mortalité pour chacun des groupes sociaux.
\end{abstract}

Mots-clés

Belgique, mortalité, inégalités sociales, différences spatiale.

1. Center for Demographic Research, UCLouvain. 


\begin{abstract}
This article offers an overview of shifts in mortality in Belgium from the nineteenth century to the present, particularly in terms of sociodemographic and spatial disparities. It analyzes these shifts in mortality according to age and sex since the early nineteenth century, drawing from a review of the literature and using data from the Human Mortality Database (HMD). For the more recent analyses (1991-2015), data from the National Register, population censuses and official death records were matched up.

In Belgium, the average life expectancy is now 80 years, twice as long as 170 years ago. As in other Western countries, however, disparities persist and sometimes even widen. There are thus major inequalities between social groups in regards to death, and these have been worsening since at least the early 1990s. These inequalities are apparent for each cause of death and ages at death, for women and for men. Spatial inequalities in mortality by region, district and residential area have also widened over at least the past quarter century. Even within similar social groups there are spatial disparities in mortality, indicating that environmental, cultural and behavioural factors affect mortality in the same way for each social group.
\end{abstract}

\title{
Keywords
}

Belgium, mortality, social inequalities, spatial differences.

\section{Introduction}

Decreases in mortality and fertility, which began to take place in Western Europe in the nineteenth century, are the main components of the demographic transition (i.e. the change from a demographic regime dominated by high mortality and fertility to one characterized by low levels of mortality and fertility). The demographic transition is linked to economic, social, cultural and political transformations in our societies over the nineteenth and twentieth centuries. Shifts in mortality rates are part of the epidemiological transition, which is the transition from a pathological environment dominated by infectious diseases (e.g., pertussis, diphtheria, tetanus, tuberculosis, smallpox) to one where chronic and non-infectious diseases prevail. Another feature of this transition is an increase in life expectancy due to societal and medical changes such as improvements in public and personal hygiene practices, diet, medical procedures and the public health system (Meslé, Vallin, 2002).

In his analysis of changes in the relative importance of causes of death, A. Omran (1971) identified three epidemiological stages or «ages» in this transition: 
- «The age of pestilence and famine», which ended around the mid-eighteenth century. Mortality was very high and dominated by infectious, transmissible and parasitical diseases; vacillations were brought about by epidemics, famines and wars. Life expectancy was scarcely between 20 and 40 years.

- "The age of receding pandemics», seen in Western countries from the second half of the eighteenth century to the interwar period. During this period epidemics became rare, despite sporadic resurgences of cholera, and there was a decline in viral, microbial and bacterial transmissible diseases. Life expectancy rose from 30 to 50 years, although in certain countries and areas the decline in mortality halted with the start of industrialization and severe crowding in extremely unhygienic conditions.

- «The age of degenerative and man-made diseases», whereby the pace of mortality decline slows down. A near-total decline of infectious diseases as cause of death gives way to the rise of chronic diseases (e.g., cardiovascular diseases, cancers), man-made diseases brought about by high-risk behaviours such as smoking and alcoholism, and violent deaths (e.g., traffic accidents, suicide) (Meslé, Vallin, 2002).

This three-stage model corresponds quite well with occurrences in Western societies until the end of the 1960s. However, the third stage did not signal the end of changes in mortality. After a period of slower growth (1955-1970), life expectancy entered a new period of steady, marked growth, mainly attributable to a major drop in cardiovascular diseases and the adoption of individual behaviours conducive to better health. This new phase has led to the epidemiological transition becoming the first step in a broader movement, the health transition, because the trends observed since the 1970s go far beyond the narrow scope of epidemiological changes alone (Vallin, Meslé, 2013).

This study falls within this theoretical and chronological framework. It aims to summarize the evolution of mortality in Belgium from the nineteenth century to the present day by focusing on social and spatial inequality. We base our analysis of these shifts in mortality according to age and sex since the early nineteenth century on a review of the literature and on data from the Human Mortality Database (HMD). For more recent analyses (1991-2015) of marital, social and spatial differences in mortality, the results of the CAUSINEQ ${ }^{2}$ project, funded by the Belgian Federal Science Policy Office (BELSPO), were used. 


\title{
Shifts in mortality in Belgium from 1840 to the present day
}

\author{
Life expectancy today is twice what it was 170 years ago
}

One of the fundamental demographic shifts in Western societies over the past two centuries is that of delayed mortality (Adveev et al., 2011). In Belgium in 1840, life expectancy at birth was nearly 40 years; by the start of the twenty-first century it had surpassed 80 years (Devos, 2010), making it one of the highest in the world today (Pison, 2015).

The changes, while major, have not been regular. In the nineteenth century they were slow, with life expectancy increasing by only about ten years between 1840 and 1900, reaching 50 years by the start of the First World War. Curves in the crude mortality rate and life expectancy at birth (Figure 1) are punctuated by periods of downturn and stagnation that reflect epidemics and economic crises.

Indeed, Belgium was hit by cholera a number of times in the nineteenth century, with each episode taking a minor or major toll. The first epidemic struck in 1832 and resulted by 8'000 victims until 1834. Cholera struck again between 1848 and 1850, this time compounding food shortages already rife since 1845 , leading to 23 '000 deaths. The 1850 s saw further epidemic outbreaks: 6'000 more succumbed to cholera in 1854, followed by a further $5^{\prime} 500$ in 1859 . The worst cholera epidemic of the century came in 1866, when the disease ravaged the entire country particularly virulently and struck down $43^{\prime} 000$ people. It resurged a final time in 1892-1893, killing a further $1^{\prime} 300^{3}$. The mortality curve was also affected by other epidemics in the 1800s, including $12^{\prime} 000$ deaths from typhus in 1846-1847 and 34'000 from smallpox in 1870-18724 (Fallon, 1942).

The «Pasteurian revolution», and especially Koch's isolation of the cholera vibrion in 1884, finally provided the tools to combat cholera effectively. More generally, advances in medical knowledge, the application of strict quarantine measures and sanitary cordons, and the development of public hygiene practices also considerably lowered the risk of epidemics (Eggerickx, Poulain, 1991).

From the start of the twentieth century, growth in life expectancy at birth is faster and more linear: after the First World War and the Spanish flu, it grew from 50 to 60 years between 1920 and 1930, followed by a period

3. Figures on numbers of deaths from cholera were obtained from the 1870, Statistical Yearbook, and from Kurborn (1897).

4. To our knowledge this smallpox epidemic has never been rigorously studied. 
of stagnation during the Great Depression of the 1930s and then a dip of a few years during the Second World War.

FIGURE 1 Changes in the crude mortality rate (\%o) and the crude life expectancy at birth (total population) in Belgium, 1840-2014

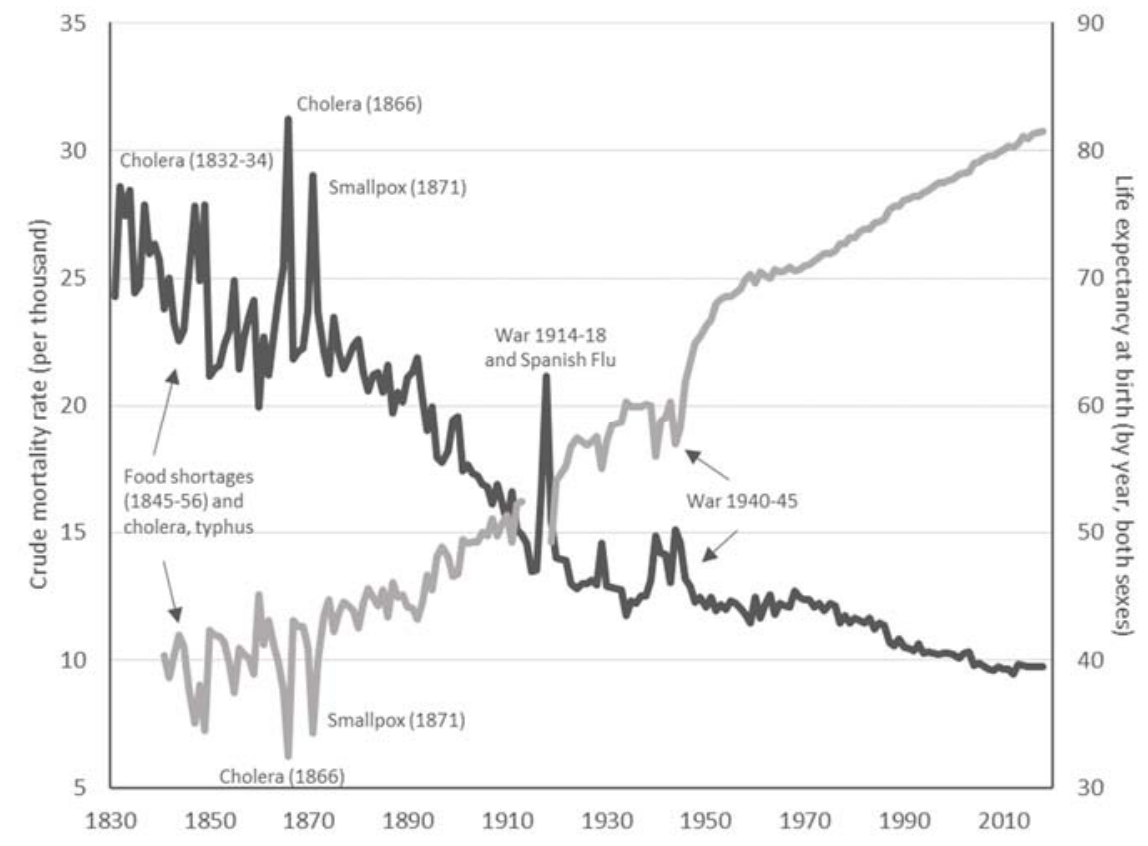

Source: Human Mortality Database.

The gap in the life expectancy curve between 1914 and 1918 reflects an absence of data for that wartime period. To date there has been no study of the impact of the war and of the Spanish flu in terms of precise mortality figures for Belgium (Eggerickx, 2014b). J. Winter (1988) proposed a figure of 240 '000 military and civilian deaths due to the war between 1914 and 1918. Although they should be interpreted with caution, «population movement statistics» that count the total number of deaths during these years do not support this estimate. Death figures for 1914, 1915 and 1916 are at a «normal» rate, then increasing in 1917 by 15'000$20^{\prime} 000$ and in 1918 by 40'000-45'000, probably due to the Spanish flu.

Since the end of the Second World War longevity has grown more quickly and steadily, despite an overall dip in the 1960s. This quasi stabilization of life expectancy at birth in most Western countries reflects "[...] the difficulties in that period in fighting cardiovascular diseases and the rise of 
diseases of 'civilization' (smoking, alcoholism, traffic accidents...)》 (Adveev et al., 2011, p. 45, our own translation). From the 1970s, medical advances in the struggle against cardiovascular diseases and cancers, along with preventative campaigns and anti-smoking measures as well as changes in diet and hygiene practices, have translated into major gains in longevity (Meslé, Vallin, 2002).

Over the 45 years between 1970 and 2015, life expectancy has risen by 10 years, from 71 to 81 , that is, an average gain in life expectancy of slightly more than two months per year, or one year every five years. Nonetheless, the gains for women have flagged somewhat over the last quarter century (Figure 2).

\section{FIgURE 2 Gains in life expectancy year on year (by year)} (moving mean over 10 years)

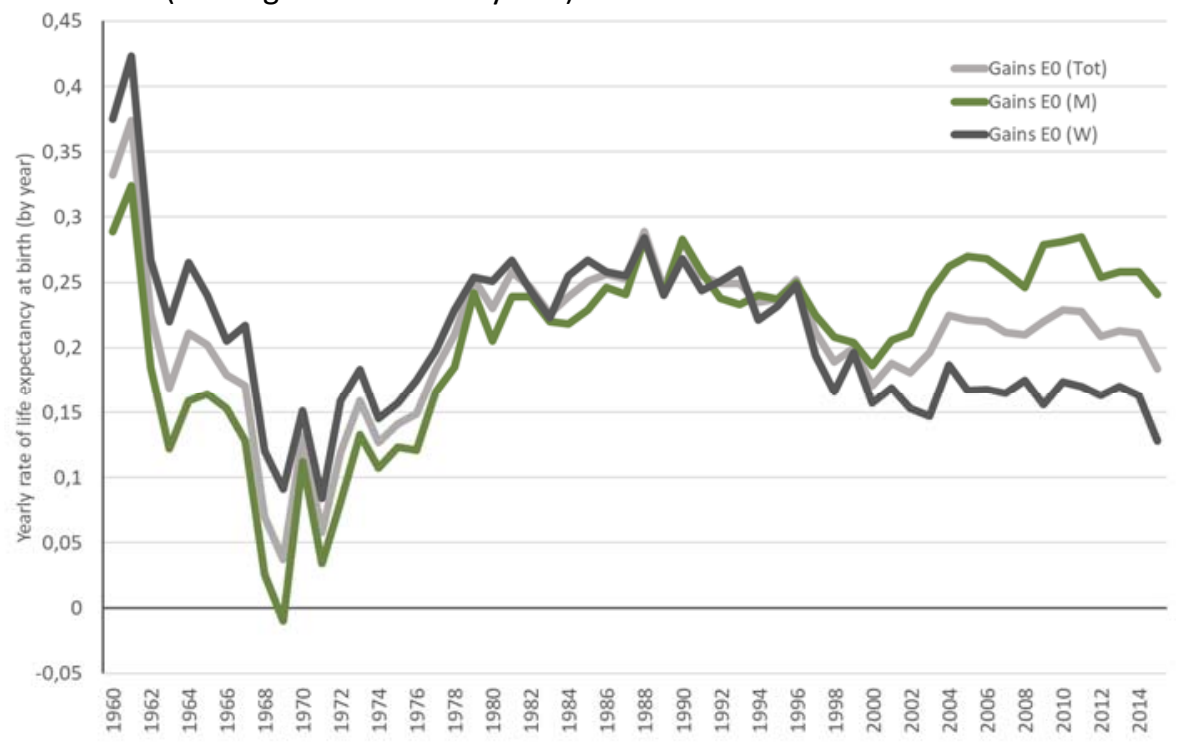

Source: Human Mortality Database.

\section{Differences in life expectancy between men and women}

From excess female mortality to excess male mortality

Within this overall progress in longevity there are disparities, most notably between women and men. How can the evolution of these disparities in longevity between the two sexes be explained (Figure 3)? First, it 
would seem that women have a biological advantage from early childhood that is difficult to quantify accurately (Vallin, 2002). In the case of Belgium, in the nineteenth century as much as today, there is an excess male childhood mortality that fluctuates between $20 \%$ and $30 \%$ (Figure 4).

Nonetheless, in Belgium, as elsewhere, women have not always had greater longevity than men. Until the mid-1800s, male and female life expectancy were very similar, and sometimes slightly higher in men (Figure 3 ), due to excess mortality among women of childbearing age and among girls during childhood and adolescence (Devos, 1996; Eggerickx, Tabutin, 1994; Poulain, Tabutin, 1977, 1981; Tabutin, 1978). Girls were indeed more susceptible to dying from infectious or parasitic diseases (measles, whooping cough, scarlet fever, pulmonary tuberculosis, etc.) because boys had the benefit of better diets and medical care (Eggerickx, Tabutin, 1994).

The gap in life expectancy has been on the increase since the second half of the 1800s, long before the decline of excess female mortality in some age groups. Women's life expectancy at birth in 1850 was one year higher than men increasing to 3.5 years around 1900. It remained at this level until 1930, then increased again until 1984 and reached its maximum value of 6.8 years, neglecting of course the peak of the 1940-45 years (difference of 8.96 years in 1940) caused by the war. After a decade of stagnation, this gap shrank quickly from the mid-1990s to reach «only» 4.5 years by 2015 .

The growth in excess male mortality since the mid-1800s is due to a number of factors. First is the decline in female mortality in childhood and during childbearing years, a consequence of women's improving sociocultural status, children being increasingly valued regardless of sex, decreases in fertility, and better conditions for women during pregnancy and in childbirth. Men, for their part, were exposed to a high and fluctuating risk of accidents in the workplace due to heavy industrialization of labour, the consequences of pathogenic behaviours such as smoking and alcoholism, and traffic accidents (Meslé, 2004; Vallin, 2002). After the Second World War women also began to adopt such noxious behaviours, as well as entering the labour market in large numbers, albeit generally in less risky jobs than men. We might expect a decrease in disparities in mortality between the sexes, and yet these continued to widen in the 1960s and 1970s. According to F. Meslé (2004, p. 334), "[Women] have compensateed for these new harmful behaviours with a much more effec- 
tive health attitude than men [...] thanks to more frequent medical consultations, earlier and more regular screening, better treatment follow-up» (our own translation).

Figure 3 Life expectancy at birth for men and women (by year)

Life expectancy at birth for men and women by sex

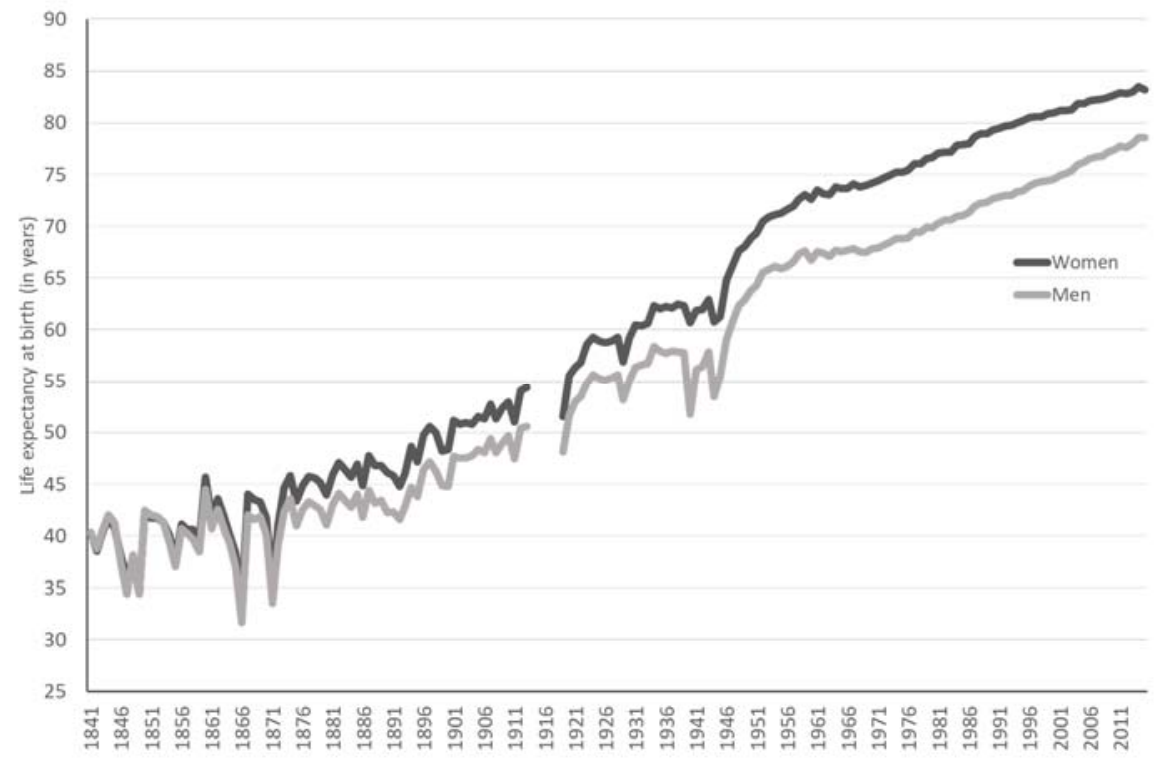

Yearly disparities in life expectancy at birth for men and women

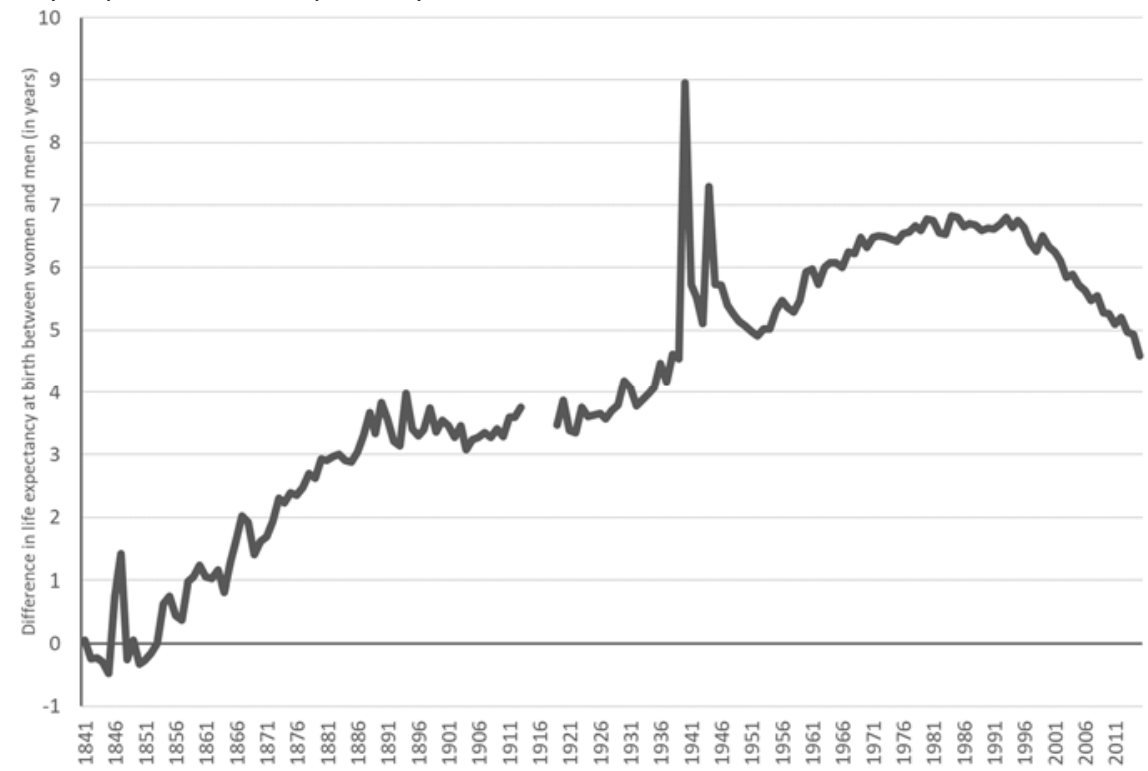
Source: Human Mortality Database. 
The gap between female and male life expectancy stabilized through the 1980 s, particularly with the noticeable drop in male mortality due to cardiovascular diseases, and then decreased from 1995 in Belgium (Figure 3). Similar trends can be seen in most Western European countries (Meslé, 2004), explained by faster progress on the male side (Figure 2), such that between 1995 and 2015 in Belgium, men gained 5.1 years of life expectancy compared to 4.1 years for women.

Shifts in differences in mortality by sex and age

As shown in Figure 4, shifts in differences in mortality by sex vary dramatically by age and by cause of death. In 1841-1844, for girls 1-18 years old the probability of dying 5 was up to $35 \%$ higher than for boys. In that same period the probability of dying for women 25-45 years old exceeded that of their male counterparts by $5 \%$ to $25 \%$.

Excessive mortality in girls, seen throughout the West in the 1800s, is attributed to women's lower status whereby girls were offered poorer nutrition, care, and hygienic conditions than boys and were thus more susceptible to falling prey to infectious and parasitic diseases (Tabutin, 1978; Tabutin, Willems, 1998). This excess mortality for girls under 18 years old persisted throughout the nineteenth century even if it weakened slightly over that time. In Belgium it only disappeared around the 1930s, as did excess maternal mortality for 25-39-year-olds (Figure 4). The latter was linked to risks associated with pregnancy, childbirth and its immediate aftermath, which "[...] were highly dependent on the economic and social conditions governing women's reproductive lives, which were closely linked to their status, and, of course, their level of fertility, itself highly associated with the cultural and social context of womanhood» (Vallin, 2002, p. 326, our own translation).

In 1900-1904, there is clear excess male mortality as of 35 years old, and it prevails to end of life, reaching a peak between 45 and 55 years, when men are $50 \%$ more likely to die than women of the same age. The pattern is nearly the same for 1930-1934, except that excess male mortality is now seen at all ages. The period 1960-1964 presents a significant change whereby excess male mortality has intensified for all ages, in addition to the appearance of two peaks: one for men aged 50-65, whose risk of dying

5. The probability of dying at a given age is a measurement of the probability or risk of a person who has survived to that age of dying before they reach the next age. It is calculated by dividing the number of deaths between two ages by the number of people alive at the first age. 
is now twice that of women in the same age group, and the other at around 20 years old, when men's probability of dying is about 2.7 times higher than women's. Between 1960 and 1990 this excess male mortality among young adults intensified and spread past the age-30 mark, while the peak for older men shifted to around 65 years 6 . We also note a net reduction in excess mortality, in 1990-1994 and 2010-2014, for men 4075 years old. This pattern for excess male mortality according to age is not unique to Belgium; France, for example, has a very similar pattern (Meslé, 2004).

FIgURE 4 Changes in the sex ratio ${ }^{7}$ of probabilities of death in Belgium

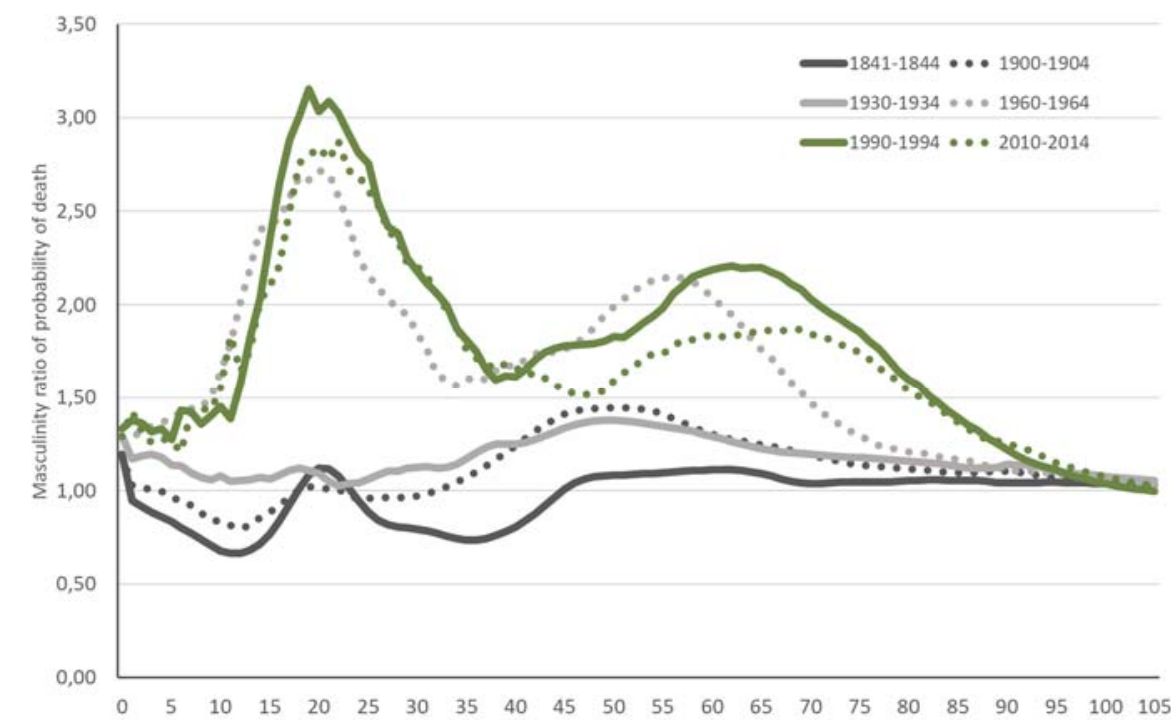

Source: Human Mortality Database.

6. The exacerbation of excess male mortality at all ages over this period, and especially between 1980 and 1990, is inconsistent with stagnation in the disparity between male and female life expectancy. As pointed out by F. Meslé (2004, p. 337), in the case of France, stabilization of these disparities is because «... gains for males at higher mortality levels have a greater impact on life expectancy, which compensates for the rise in excess mortality» (our own translation).

7. This is the ratio, at a given age, between the probability of dying for men and the probability of dying for women. A ratio of greater than 1 indicates excess male mortality, and below 1 , excess female mortality. 
Ratios for probability of dying do not take into account the significant variability of mortality quotient by age and their relative importance in differences in life expectancy between men and women.

These impacts can be taken into account by breaking down differences in life expectancy between sexes, using the method developed by Pressat (1985). This method allows for estimation of the impact of each age or age group on differences in life expectancy between the two sexes (Table 1).

TABLE 1 Age decomposition of difference in life expectancies at birth between sexes in Belgium (in year)

\begin{tabular}{|c|c|c|c|c|c|c|c|c|}
\hline & $\begin{array}{c}1841- \\
1845\end{array}$ & $\begin{array}{c}1860- \\
1864\end{array}$ & $\begin{array}{c}1880- \\
1884\end{array}$ & $\begin{array}{c}1900- \\
1904\end{array}$ & $\begin{array}{c}1930- \\
1934\end{array}$ & $\begin{array}{c}1950- \\
1954\end{array}$ & $\begin{array}{c}1980- \\
1984\end{array}$ & $\begin{array}{c}2010- \\
2014\end{array}$ \\
\hline $0-<1$ & 1.24 & 1.33 & 1.38 & 1.60 & 1.50 & 0.79 & 0.25 & 0.07 \\
\hline $1-14$ & -0.85 & -0.27 & -0.11 & 0.07 & 0.31 & 0.21 & 0.08 & 0.05 \\
\hline $15-29$ & -0.27 & -0.26 & 0.05 & -0.09 & 0.14 & 0.39 & 0.60 & 0.33 \\
\hline $30-59$ & -0.52 & 0.03 & 1.10 & 1.11 & 1.12 & 1.93 & 2.00 & 1.20 \\
\hline $60-74$ & 0.17 & 0.19 & 0.45 & 0.57 & 0.67 & 1.34 & 3.37 & 1.86 \\
\hline $75+$ & 0.04 & 0.03 & 0.07 & 0.12 & 0.41 & 0.35 & 0.39 & 1.59 \\
\hline Total & -0.19 & 1.05 & 2.94 & 3.37 & 4.15 & 5.01 & 6.70 & 5.10 \\
\hline
\end{tabular}

Source: HMD.

Excessive male mortality at under 1 year old was a determining factor in the differences between male and female mortality for much of the nineteenth century. Indeed, in 1841-1845, this factor almost completely offsets excess mortality in girls 1-14 years old and for women 15-59 years old. In 1860-1864 it was almost solely responsible for overall excess male mortality. Although its effect was not as strong twenty years later, it continued account for over $40 \%$ of differences in life expectancy between sexes. Although excess male mortality at under 1 year old has remained quite constant over time, its impact on differences in mortality between sexes has plummeted as infant mortality has decreased and excess male mortality for the other age groups has risen. Thus, near the end of the 1800s excess mortality for men 30-59 years old accounted for nearly $35 \%$ of overall excess male mortality; this phenomenon has remained relatively stable to this day, hovering between $25 \%$ and $35 \%$. Up to the start of the Second World War excess mortality for men 60-74 years old accounted for less than $20 \%$ of overall excess male mortality; this proportion climbed to a peak of $50 \%$ in the 1980 s, falling back down to $40 \%$ in 2010-2014. This latter period is characterized by a marked increase in 
excess mortality for men over 75 years old, which accounted for more than a third of excess male mortality.

\section{The steady shifting of mortality to older ages: A major phenomenon}

Until the start of the twentieth century, death often occurred at a very young age, whereas as of the second half of that century, most deaths took place in old age.

The rising in age of death is illustrated in Figure 5, showing the number of survivors at each age from life table (both sexes) with 100 '000 persons as radix. In 1841-1844, a quarter of the population had died before reaching 5 years of age, and half before 44 years, while only $32 \%$ survived at 65 years. As of the start of the twentieth century, the curves move away from the 1841-1844 one, flatting out progressively between 0 and 60 years with individuals living longer, and then rising steeply after 60 years, with individuals dying at higher ages and within an ever-decreasing age span. In 1900-1904, before 60 years, half the initial population had died. This threshold increases to 69 years for 1930-1934, and 84 years for 2010-2014 (Figure 6). We also observe that for 2010-2014, 62\% of deaths occur at over 80 years, compared to $32 \%$ in $1960-54,12 \%$ in 1900-1904, and 10\% in 1841-1844.

\section{Figure 5 Changes in survival curves by age for total population}

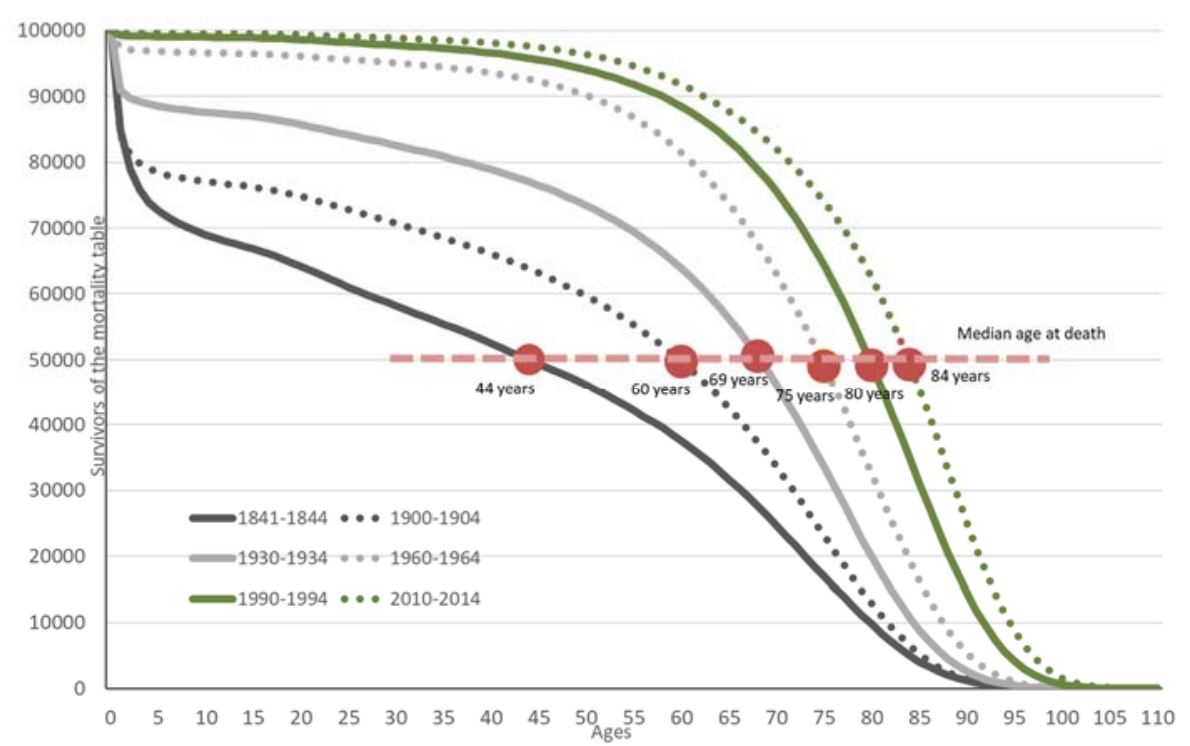

Source: HMD. Note: red dots represent median age at death. 
Decreasing child mortality

Not all ages have contributed with the same intensity and timing to the increase in life expectancy that characterized the 19th and 20th centuries. The evolution of child mortality has initially played an important role, but it is necessary to distinguish the situation of children under one year of age, from that of children aged 1 to 4 years and their elders ( 5 to 9 years) (Figure 6).

Shifts in infant mortality (between 0 and 1 year old) is a determining factor in the demographic transition and the decline in mortality in general (Rollet, Bourdelais, 1993). Although data is sparse, it appears that a first phase of decreases in infant mortality took place at the turn of the eighteenth to nineteenth century, spurred by the first vaccination campaigns against smallpox, changes in feeding practices for newborns, and improvements in childbirth management techniques ${ }^{8}$ (Poulain, MasuyStroobant, 1983). This progress stalled as of the 1840s as Belgium began a process of industrialization and rapid and chaotic urbanization that saw a degradation of the hygienic environment, problems with supply, and women entering the workforce, especially in the textile sector ${ }^{9}$. These factors directly or indirectly sparked a resurgence in mortality among children, who are highly susceptible to infectious diseases, such as measles, scarlet fever, and especially enteritis and diarrhoea (Masuy-Stroobant, 1983). This deterioration in living conditions in urban and industrial environments was exacerbated by an agricultural and food crisis that, over the decade 1846-1856, led to impoverishment among the rural population, especially in the north of the country (Eggerickx et al., 2012).

Later, improvements in the survival of children less than a year old were thwarted by cholera and smallpox epidemics and a deterioration in living conditions brought about by the major economic depression of 18731892 (Eggerickx et al., 2012). In the 1800s, on average, a quarter of all deaths annually were infant deaths, and one newborn in 5 or 6 did not make it to its first birthday (Figure 6).

Overall, in the nineteenth century there was no substantial decrease in infant mortality, and infant mortality made no contribution to improving life expectancy in the second half of the century (Devos, 2010) (Table 2).

8. Unlike in France, the use of wet nurses was rare in Belgium (Debuisson, 2015).

9. In the textile industry, where the labour force was mainly women, many mothers had to return to work as quickly as possible after childbirth, thus cutting short breastfeeding (Masuy-Stroobant, 1983). Lack of mother's milk and early weaning increased the risk of babies dying in this period. 
FIGURE 6 Changes in mortality in children under 1 year old (1q0), 1-4 years ( $4 q 1)$, and $5-9$ years ( $5 q 5)$ in Belgium

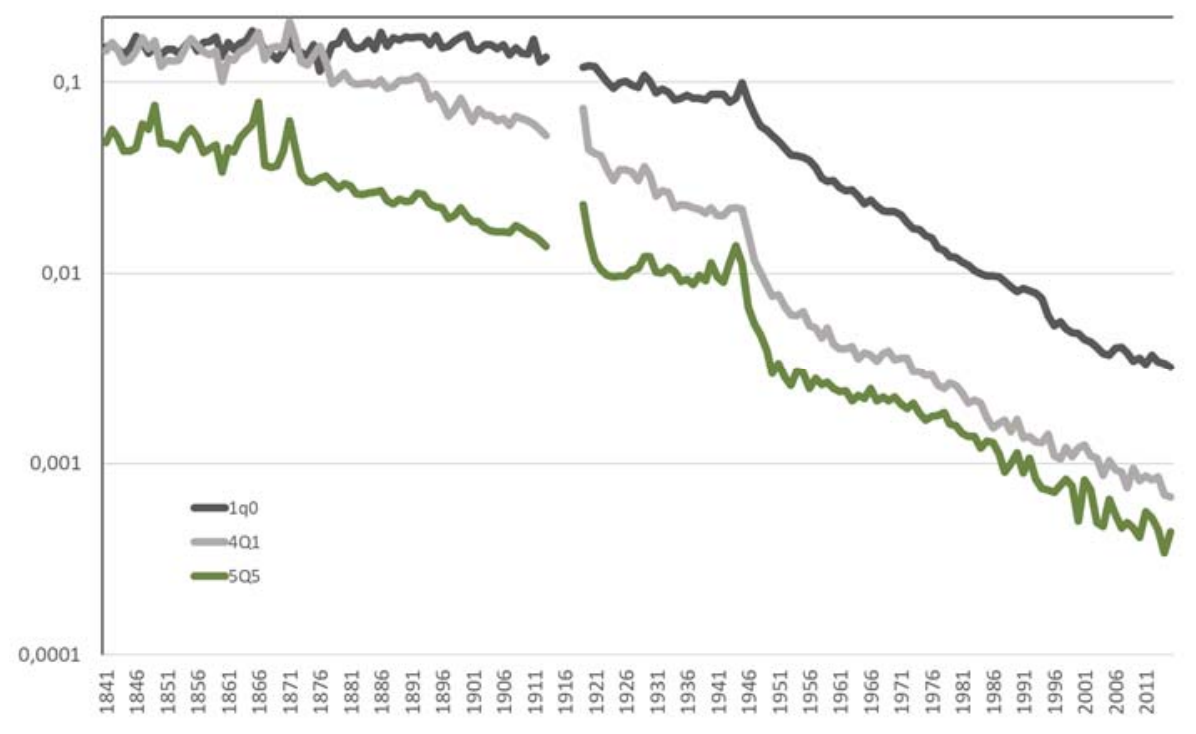

Source: HMD.

The situation changed definitively around 1900, manifesting as a steady and rapid decrease in mortality among children under 1 year old. Such decreases had already begun for older children: around 1880 for 1-4year-olds, and around 1850 for 5-9-year-olds (Figure 6). These young children, and by association adolescents 10-14 years old, are primarily responsible for improvements in life expectancy in the second half of the nineteenth century: the decrease in their mortality between 1840 and 1900 led to a gain of 6 years life expectancy, or $70 \%$ of total gains in that period (Table 2).

TABLE 2 Absolute contribution (in years) of age groups to changes in life expectancy at birth in Belgium

\begin{tabular}{|l|c|c|c|c|c|}
\hline Ages & $1841-1904$ & $1905-1934$ & $1935-1954$ & $1955-1984$ & $1985-2014$ \\
\hline $0-<1$ & -0.48 & 4.34 & 3.13 & 2.60 & 0.60 \\
\hline $1-14$ & 5.93 & 2.70 & 1.95 & 0.48 & 0.23 \\
\hline $15-29$ & 1.71 & 0.76 & 1.43 & 0.22 & 0.36 \\
\hline $30-59$ & 1.16 & 1.50 & 1.71 & 1.29 & 1.45 \\
\hline $60-74$ & 0.11 & 0.47 & 0.59 & 0.99 & 2.23 \\
\hline $75+$ & -0.05 & 0.12 & 0.19 & 0.62 & 1.77 \\
\hline Total & 8.39 & 9.89 & 9.02 & 6.21 & 6.65 \\
\hline
\end{tabular}


As of the start of the 1900s, the decrease in mortality in infants under 1 year old significantly contributed to the increase in life expectancy. Between 1900 and 1934, the decrease in mortality for children under 1 year old accounted for a gain of 4 years life expectancy, and for 1-14-year-olds, a gain of 3 years. In relative terms, $75 \%$ of gains in life expectancy between 1900 and 1934 are linked to decreased mortality among those less than 15 years old. Since that period their influence on the increase in lifespan has weakened, though it remained significant until the mid1980s. Thus, from 1955 to 1984, decreasing infant mortality continued to account for $40 \%$ of the overall increase in life expectancy, even while the proportion of gains in mortality for 1-14-year-olds dropped significantly (10\%). Over the past three decades the 0 -14 year-olds contribution to life expectancy increases has shrunk markedly, dipping below $15 \%$.

Major decreases in child mortality for the entire period can be explained by a series of factors, including the decline in fertility, as small families can devote more of their economic and emotional resources to each of their children. In addition, improvements in personal and public hygiene, policies for the protection of children, the boom in childcare services, the development of dietary practices more appropriate for children and the rooting out of unfavourable ones, such as the promotion of breast milk over unpasteurized milk, improved standard of living, better monitoring of pregnancies, and scientific progress against infectious diseases have all contributed to better chances of survival for children, while adolescents have benefited from a decline in child labour (Masuy-Stroobant, 2010).

\section{Changes in life expectancy at older ages}

Life expectancy has also increased for older people (Devos, 2010). While it remained virtually unchanged between 1841 and 1945, life expectancy at 65 years climbed steeply after the Second World War, with quick and regular progression as of the 1970s (Figure 7). This overall pattern is obvious for women, whose life expectancy at 65 years increased from 13.4 years in 1945 to 21.2 years in 2015, a gain of 8 years over a period of 70 years. For men, the lifespan of 65-year-olds only began increasing as of 1980, going from 12.9 years in 1980 to 18.0 years in 2015, thus gaining 5 years over a period of 35 years. 


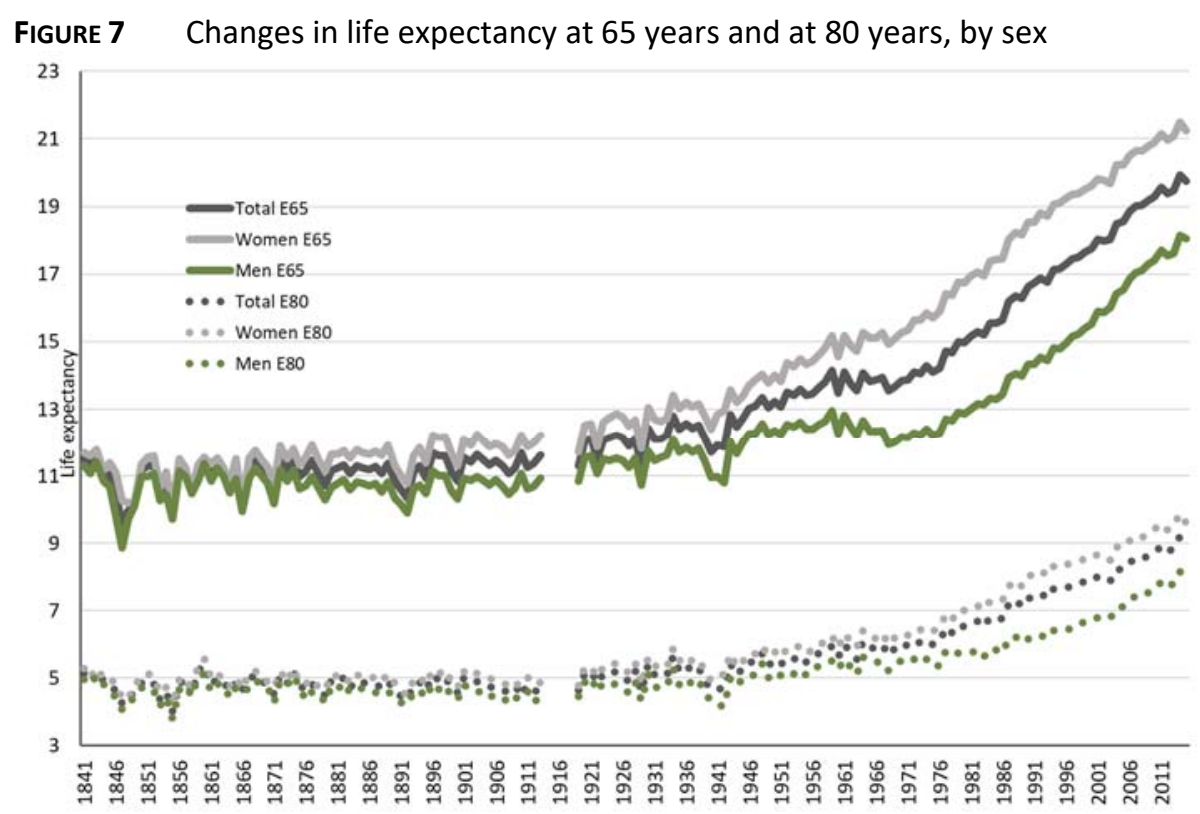
Source: HMD.

This same time lag according to sex is seen in life expectancy at 80 years. It was not until the 1970s for women, and the 1990s for men, that lifespan at 80 years began to rise. For women, life expectancy at 80 years in 1970 is 6.3 years, and in 2015 nearly 10 years, while for men, these figures are 6.2 and 8.1 years respectively, a gain of 2 years over a quarter of a century.

The time lag between sexes in the progression of life expectancy at 65 and 80 years gives rise to a gap in longevity, as shown in Figure 7. Thus, as of the 1950s, 65-year-old women pull distinctly ahead of men, as they do at 80 years old as of the 1970s (Figure 8).

Nonetheless, since the 1990s, the gap in life expectancy between sexes at 65 years old and at 80 years old has shrunk. This reduction is mainly explained by the lifestyles and behaviours of men and women getting more similar. Indeed, men have increasingly adopted preventative behaviours practised by women, and this has translated into them living longer. Meanwhile women have adopted some male behaviours that are not so favourable for health. 
FigURE 8 Changes in the gap in life expectancy at older ages (women minus men)

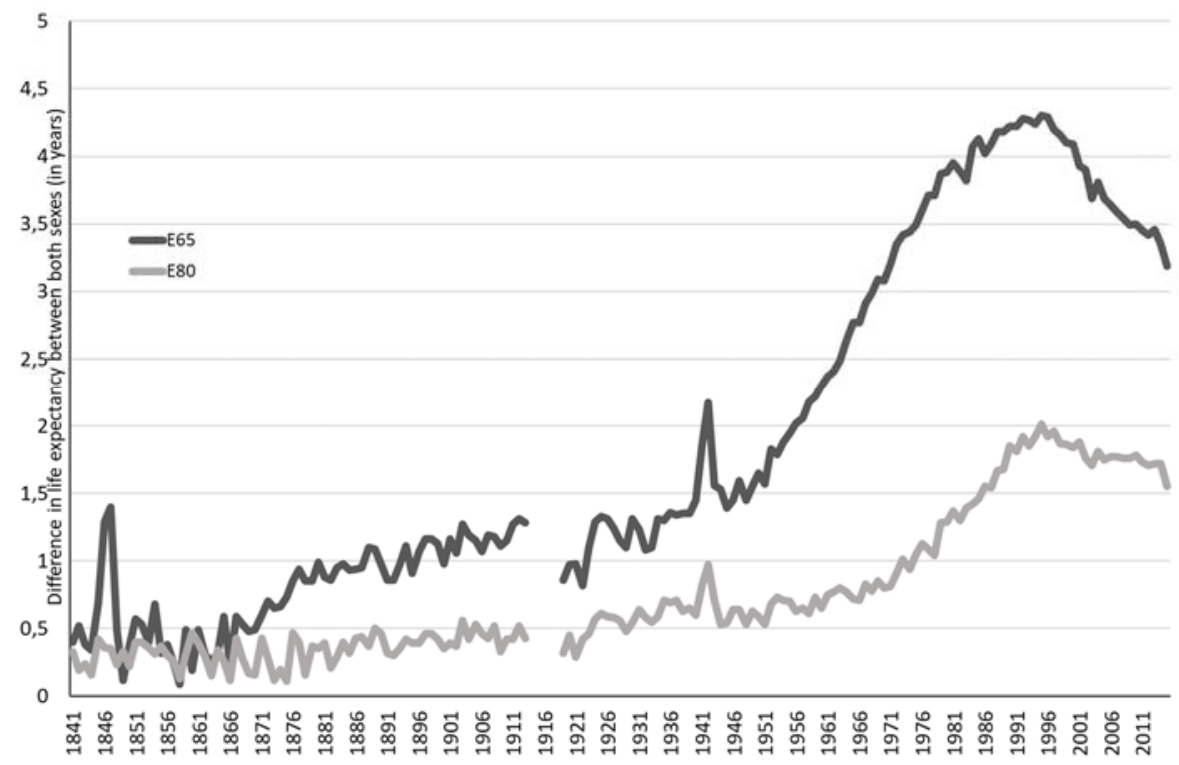
Source: HMD.

The decreasing disparity between sexes in terms of life expectancy since 1990 is also due to a slowing down in the gain in life expectancy at the oldest ages. Thus for women, who live longer than men, increasing their life expectancy becomes progressively more difficult, while men, who are far behind, are able to achieve gains more quickly and easily.

At any rate, in the second half of the twentieth century those aged 60 years or more played a central role in the rise in life expectancy thanks to decreases in mortality at the oldest ages. While until 1955 the contribution of the 60+ group to increasing life expectancy remained minor at less than 10\%, it later became more distinct: between 1954 and 1984, they were responsible for $25 \%$ of gains in life expectancy, increasing to $60 \%$ between 1984 and 2014. In other words, over the past 30 years, the $60+$ age group has become the main factor in the rising life expectancy (Table 2). 


\section{Social inequalities in mortality}

\section{State of the research and theories}

The social inequalities in terms of mortality and health are well known and deeply anchored in the history of our societies (Lagasse et al., 1990; Mizrahi, Mizrahi, 2002; Valkonen, 2002). From the second half of the nineteenth century, the social disparities of mortality have been the subject of numerous debates involving three «explanatory approaches»: hereditary, environmentalist, and behavioural. The first approach assumes that social status is the result of skills and characteristics that are naturally inherited. The second points to standard of living and the work conditions associated with massive industrialization, while the third considers that excess mortality among the underprivileged classes is a function of harmful and reckless habits and behaviours. These debates laid the ground for the explanations given for social inequalities in mortality in the Black Report ${ }^{10}$ (Macintyre, 1997). These explanations included selective effects under the assumption that it is health status that determines social status and not the reverse; cultural and behavioural factors (alcohol consumption, smoking, dietary choices, etc.) specific to class; socioeconomic characteristics of individuals (income, level of education, conditions in the work and the home, etc.); and measurement errors linked to availability and quality of data (Macintyre 1997; Valkonen, 2002). While none of these explanatory categories can be ruled out, most studies consider individual socioeconomic factors to be at the root of inequalities in health and mortality (Herjean, 206; Link, Phelan, 1995; Van Oyen et al., 2010). Many studies have also shown that differences in mortality and morbidity follow a definite socioeconomic slope (Van Oyen et al., 2010): in other words, the higher a person's position in the social scale, the higher her life expectancy.

Other explanations have since been advanced (Mackenbach, 2012). Thus, mortality in adult age would be partly determined by past biological and social conditions (this is the life-course perspective). Studies have also demonstrated that the Big Five personality traits (openness, conscientiousness, extraversion, agreeableness, neuroticism) as well as individual cognitive skills vary according to social environment, accounting in part

10. The Black Report was a document published in 1980 in the United Kingdom by the Department of Health and Social Security. The study, led by Sir Douglas Black, aimed to summarize knowledge about the impact of social inequalities on health (Macintyre, 1997). 
for differences in mortality. These differences may also be linked to psychosocial factors, such as stress due to financial duress and job insecurity or a lack of social support (family, friends), factors that tend to most affect the underprivileged (Mackenbach, 2012).

At the more general level, issues of health and the prominence of mortality also depends on the provision and quality of public policies such as health care, the social security , and the education system - and thus on sociopolitical regimes (Coburn, 2004).

Beyond the mere identification of mortality disparities, what about their evolution? There was once a strong idea that declining mortality and very low levels of mortality would significantly reduce differences between social classes (Antonovsky, 1967). This idea has since been refuted by numerous empirical studies (Cambois, Jusot, 2007; Jasilionis et al., 2014). According to Link and Phelan's (1995) «fundamental causes» theory, socioeconomic disparities in terms of health and mortality are inherent in Western countries through every phase of the health transition. Whatever the main risk factor(s) for mortality, the privileged social groups always have access to and are able to wield the necessary resources (the «fundamental causes») - income, knowledge, power, social networks - to effectively counterbalance any (new) risk factors by way of preventive attitudes, access to the most effective treatments, etc.). Similarly, Jasilionis and colleagues hypothesized that «... the better-off sections of the population are also the most likely to benefit from advances in medical technology and improved health conditions, and they are the ones who benefit first. It is only with delay that the rest of the population acquires the capacity to access the same means of combating disease and death.» (Jasilionis et al., 2014, p. 590, our own translation). Empirical studies in Finland, Sweden, and Norway have shown that while each major advance in health brings about divergences among social groups in the evolution of mortality, these do not necessarily eventually converge, with the non-pioneering groups following «... their own path according to specific determinants that cause their respective mortalities to evolve at different paces» (Jasilionis et al., 2014, p. 608, our own translation).

Finally, Coburn (2004) developed a complementary hypothesis, more focused on the evolution of the socio-political structure of our societies. The increase in health and mortality inequalities would be the result of the increase in social inequalities linked to the development of neoliberalism and the decline in the influence of the welfare state, which results in disinvestment in social and health systems.

There are thus many theories and hypotheses on the causes and growth of social disparities in health and mortality; the various risk factors they 
point to, which are often interrelated, probably all have their effect, but their respective importance is difficult to determine through empirical means (Valkonen, 2002).

\section{Data and the measurement of social inequality in terms of deaths}

Deaths by social category have rarely been the subject of published statistics. It's the case of Belgium, a country that by the mid-1800s, through the efforts of Adolphe Quetelet, established a highly efficient statistical apparatus, which it quickly applied to mortality, producing, for example, numerous mortality tables as of 1830 and, starting in 1886, statistics on cause of death broken down by commune, age, and sex. Yet, to our knowledge Belgium has never produced any official statistics on death by occupational groups or by level of education ${ }^{11}$, even though death certificates of the present days contain this information and nineteenth-century certificates also included profession of the deceased. There is also the issue of harmonization of occupational groups between the numerator (those deceased) and the denominator (population at risk), often drawn from different sources (for example, official records for the numerator and census data for the denominator) and thus collected in different ways (Valkonen, 2002).

The matching up of individual census data with vital statistics death records was an important and decisive step forward in measuring social inequalities in mortality and their accuracy. France, Great Britain joined by the Scandinavian countries and the United States were pioneering countries in this field. (Gadeyne, 2006). In Belgium it was made possible by matching up individual data from the National Register (demographic data) with population census data (socioeconomic and housing data) and the official death register.

Another problem concerns the measurement of social inequalities. There are many factors at play in terms of individual social positioning: level of education, employment status, housing and income (Cambois, Jusot, 2007; Kunst, Mackenbach, 1994). While these factors are highly correlated, they can still have different effects on health and mortality. Thus

\footnotetext{
11. A number of recent studies have analyzed mortality according to level of education or social group by matching up data from the National Register, population censuses, and official death certificates (Eggerickx et al., 2018-2; Renard et al., 2017a-b; 2019). Information and data can also be found on the Sciensano site: www.healthybelgium.be/en/ health-status/health-inequalities.
} 
educational level, a measure of knowledge and cultural capital, also determines prevention, access to and use of health care services, while income, occupational category, and housing conditions relate more to standard of living (Cambois, Jusot, 2007) and thus to material resources.

Faced with the difficulty of combining the different dimensions of social positioning - given the information available, particularly in the form of individual data, and their potential for matching them with that relating to individual deaths - most studies focus on only one dimension. Often this is level of education, considered as a good proxy for individual socioeconomic characteristics (Galobardes et al., 2007; Machenbach, Kunst, 1997; Van Oyen et al., 2010). This variable is also not very susceptible to change over time and does not vary by proximity of death, which is not the case of, for instance, income and employment category (Valkonen, 2002).

However, it is no longer the case that a high level of education guarantees a favorable or very favorable position on the social ladder. The same applies to other dimensions as well. As highlighted by F. Jusot (2003), in France, beyond the correlation that exists between income and social category indicators, variation within each group by educational level or employment category is much wider than between groups. What really determines individuals' social situation is their status for each of the various dimensions.

As part of the Causineq project, a multidimensional indicator was developed that uses a scoring method to divide the country's population into social groups. This indicator is based on three factors linked to social inequality, drawn from population censuses: level of education, occupation category, and housing characteristics. Each individual is assigned a score according to their status for each of the dimensions, their sum of scores varying between 0 and 10 . For «children» who have not completed their studies, are still maintained by their parents and do not have their own accommodation, they are given the highest score of both parents. To make analysis easier and especially avoid the issue of small numbers (rarity or absence of deaths), for each census individuals have been grouped into quartiles by score representing four social groups: underprivileged, mid-low, mid-high, and privileged (Eggerickx et al., 2018b). Data from censuses, the National Register, and official death certificates having been 
matched up, mortality tables were calculated for the observation periods ${ }^{12} 1992-1996,2002-2006$, and 2011-2015 by social group, sex, region, and district of residence.

This method of grouping scores into quartiles allows for the monitoring, to a large degree, of the impact of composition of population linked with change in our societies. Let us take the example of level of education. Over recent decades the educational level of the population has increased overall: more and more people have a university education, and fewer and fewer have no diploma. In other words, social differences in mortality based on this single variable and on the dichotomy of «no diploma versus a university degree» apply to an ever-smaller population at the bottom of the social ladder, the effect of which is to reduce the social and political significance of the inequalities thus demonstrated, since the highest mortality rates were seen in a population that is numerically shrinking. With score quartiles, on the other hand, the person-years associated with each social group are virtually identical, rendering the differences and changes all the more significant. In addition, with each census the least privileged quartile is composed of people who are more and more educated, while in the most privileged quartile the weight of those with university degrees also increases. The indicator therefore takes into account the overall change in educational attainment, in the same way changes in the housing conditions and socio-professional status (Eggerickx et al., 2018b).

\section{In Belgium, the social inequalities of mortality are significant and growing}

The rising life expectancy for more than a century now is a remarkable sociodemographic development, but not everyone has benefited from it in the same way. Social inequalities with regards to death persist: according to Mackenbach (2012), there is a disparity in life expectancy of an average of 5 to 10 years between the two extremes of the social hierarchy in developed countries. In addition, recent decades have seen a widening of the mortality gap between the social classes in many countries (Cambois, Jusot, 2007). In the UK and the USA there is even stagnation, and

12. Databases for the observation period 1991-2017 are automatically matched through individual identification codes; data from the National Register prior to that is not available. 
indeed drops, in life expectancy at birth ${ }^{13}$, the root causes of which are a major escalation in socioeconomic inequalities and access to health care becoming progressively more difficult for some social groups (Ho, Hendi, 2018).

Does this situation apply in Belgium? There have been few studies on Belgium's social inequalities of mortality. In her thesis on socioeconomic differences in mortality for over 15 years of age in the early 1990s, S. Gadeyne (2006) showed that at all ages and sexes there were significant differences in mortality for all socioeconomic variables, considered separately: education, status and type of occupational class and quality of housing. Other studies have analyzed changes in life expectancy at 25 years old according to level of education between 1991 and 2001 (Deboosere et al., 2008; Van Oyen et al., 2010). Disparities were significant and their growth during that period took place proportionally more quickly for women than for men. In 1991, the life expectancy at 25 years for men with a tertiary education degree was 52.7 years, but 47.5 years for men with no diploma, a difference of 5.2 years. This difference has reached 7.4 years by $2001^{14}$.

For women, for the same levels of education, the difference grew from 3.2 years in 1991 to 6 years in $2001^{15}$ (Van Oyen et al., 2010). Not only that, these inequalities in risk of dying apply not only to the extreme categories but also to those in the middle, thus confirming the existence of a social slope for risk of dying.

In two recent studies (Eggerickx et al., 2018a-b), the social inequalities of mortality were measured using the multidimensional indicator mentioned above. Based on score quartiles, 4 social groups were identified and the results were also presented for those whose score is in the top $5 \%$ most favourable and most unfavourable, i.e. those who cumulate the best and worst positions on each of the variables (Table 3).

In Belgium, the gap in life expectancy between social groups (score quartiles) at either extreme of the social pyramid is, for the 2011-2015 period,

13. In many Western countries, including Belgium, life expectancy at birth dropped slightly between 2014 and 2015, attributed to a particularly bad flu season. This drop was followed by a resurgence in life expectancy in 2016, except in the USA and the UK (Ho, Hendi, 2018).

14. 47.6 years for men without diploma and 55 years for those with a tertiary education degree.

15. In 1991, the life expectancy at 25 years for women with tertiary education degree was 57.7 years, but 54.5 years for those without diploma. In 2001, these figures were 59.9 and 54.0 years, respectively. 
9 years for men and 6 years for women. A comparison of the $5 \%$ of the population with the lowest scores with the 5\% with the highest scores shows that differences climb to about 13 years for men and 10 years for women. As with level of education, life expectancy varies according to social ladder, for men and for women and for all three observation periods.

According to the mortality table for 2011-2015, there is a difference of 5 years in life expectancy at birth between the men and the women. Disparities vary around this average according to social group. The least privileged group has the greatest inequalities between sexes and these inequalities shrink along the social ladder. Thus for the underprivileged group (25\%), the difference in life expectancy between the two sexes is 6.5 years, but only 4 years at the top of the social scale. The situation is the same for the earlier observation periods (Table 3).

TABLE 3 Changes in life expectancy at birth (in years) by social group (SG) and sex

\begin{tabular}{|c|c|c|c|c|}
\hline Social groups & 1992-1996 & $2002-2006$ & 2011-2015 & $\begin{array}{c}\text { Increases between } \\
\text { 1992-1996 } \\
\text { and 2011-2015 }\end{array}$ \\
\hline \multicolumn{5}{|l|}{ Men } \\
\hline Underprivileged SG (5\%) & 65.6 & 68.3 & 70.2 & 4.6 \\
\hline Underprivileged SG (25\%) & 69.6 & 72.0 & 73.9 & 4.3 \\
\hline Mid-low SG & 73.5 & 76.7 & 78.1 & 4.6 \\
\hline Mid-high SG & 75.4 & 78.4 & 80.0 & 4.6 \\
\hline Privileged SG (5\%) & 78.3 & 81.9 & 82.8 & 4.5 \\
\hline Privileged SG (25\%) & 78.0 & 80.7 & 83.0 & 5.1 \\
\hline Total & 73.3 & 75.8 & 78.1 & 4.8 \\
\hline \multicolumn{5}{|l|}{ Women } \\
\hline Underprivileged SG (5\%) & 75.3 & 76.6 & 76.6 & 1.3 \\
\hline Underprivileged SG (25\%) & 78.3 & 79.6 & 80.4 & 2.1 \\
\hline Mid-low SG & 81.1 & 83.3 & 84.1 & 3.0 \\
\hline Mid-high SG & 82.2 & 84.3 & 84.8 & 2.6 \\
\hline Privileged SG (5\%) & 83.4 & 85.9 & 86.8 & 3.4 \\
\hline Privileged SG (25\%) & 83.1 & 85.6 & 87.0 & 3.9 \\
\hline Total & 80.1 & 81.7 & 83.1 & 3.0 \\
\hline \multicolumn{5}{|l|}{ Differences women/men } \\
\hline Underprivileged SG (5\%) & 9.7 & 8.3 & 6.4 & \\
\hline Underprivileged SG (25\%) & 8.7 & 7.6 & 6.5 & \\
\hline Mid-low SG & 7.6 & 6.6 & 5.9 & \\
\hline Mid-high SG & 6.8 & 5.9 & 4.9 & \\
\hline Privileged SG (5\%) & 5.1 & 4.0 & 4.0 & \\
\hline Privileged SG (25\%) & 5.1 & 4.9 & 4.0 & \\
\hline Total & 6.8 & 5.9 & 5.0 & \\
\hline
\end{tabular}


How have social differences in mortality evolved over the past quarter century? There were improvements in life expectancy at birth for all social groups, but not all at the same pace; it was slower for the underprivileged $(+4.3$ years for men and +2.1 for women) and faster for the privileged $(+5.1$ years for men and +3.9 for women). In other words, social inequalities in mortality have increased, and they have done so proportionally more for women than for men (Table 3).

Inequalities in mortality according to age and the impact of age on changes in life expectancy according to social group

There are two ways of measuring the effects of age. One way is to calculate the ratio of probabilities of dying as follows: the probability of a social group is divided by the probability of the total population. The result measures the relative differences according to age for this social group. Another is to calculate the contribution of each age class to changes in life expectancy between two observation periods or to differences in life expectancy between social groups (Pressat, 1985).

Figure 9 shows the relative probability of dying by age according to social group, with the reference group being the entire national population. The underprivileged group is characterized by excess mortality at all ages and for both sexes, just as the privileged group is by under-mortality. In addition, the intensity of excess mortality or under-mortality varies according to age. For men, excess mortality for the underprivileged group is most striking between 25 and 50 years old: in this period the risk of dying is twice as high than for the total population, and 4 to 5 times higher than for the privileged group. There are also major differences between these two social groups for children 0-5 years old. The picture is similar for female social groups. This structure of differential mortality by age and sex is similar to that observed in Finland for occupational categories (Valkonen, 2002). 
FIGURE 9 Relative probability of dying (\%) according to age,

2011-2015 (total population = index of 100)
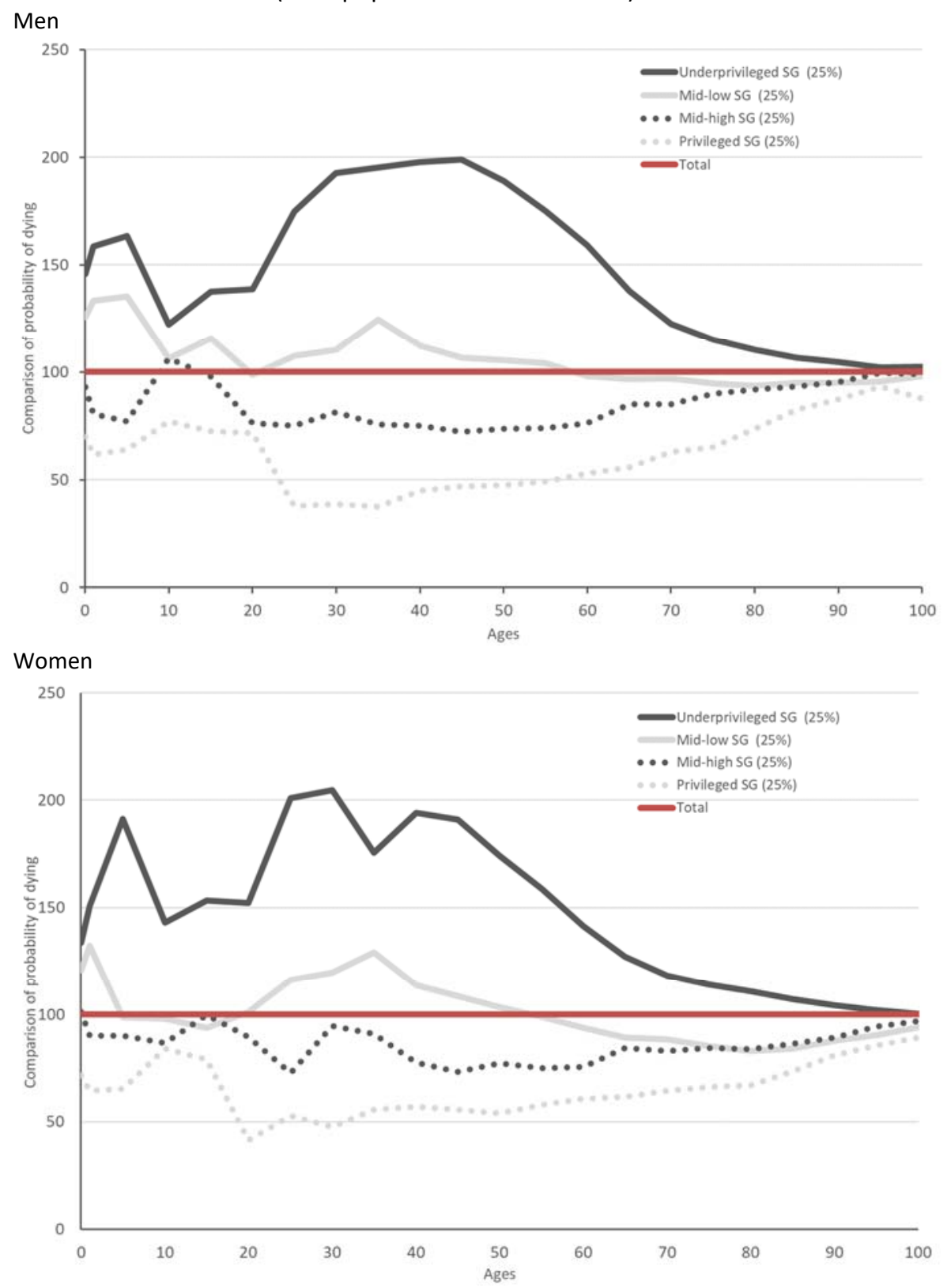

Sources: National Register, censuses. 
What are the ages most affected by the increasing social inequalities of mortality? For each period of observation, for men and women, we compare probability of dying by age for the underprivileged group to those of the privileged group. A result higher than 100 indicates excess mortality compared to the favoured group, while below that level there is undermortality (Figure 10). For men at all ages - apart from 10-19 years and over 85 years - social inequalities in death grow significantly with time. This trend is especially strong for 25-50-year-olds, when excess mortality for the underprivileged is highest. Taking as an example men 25-30 years old in 1992-1996 the risk of dying in the underprivileged group was 3.5 times higher than in the privileged group; in 2002-2006 the risk rises to 4 times as high, and then 5 times as high for 2011-2015. Similarly for women, the risk of dying at all ages increased between the base and the top of the social ladder, with a shift in the maximum differential between the underprivileged and privileged groups from 25-30 years to 20-25 years.

If the relative differences between social groups are most marked for young adults, at these ages the risk of dying is inherently very low. In other words, these relative differences, even if they are pronounced, have but a moderate impact on the evolution of differences in life expectancy at birth between social groups. It is therefore important to determine the weight of the different age brackets in terms of changes in life expectancy according to social group.

It has been demonstrated that certain diseases have more impact than others on social inequalities in death: for instance, stroke, cardiac arrest, and cancer of the lung and aero-digestive tract for men, and cancer of the stomach and uterus for women (Billiet, 2010; Renard et al., 2017b). Preventative behaviours also have a socioeconomic dimension; diagnoses are often earlier among the privileged, a group also more responsive to prevention campaigns (Willems et al., 2007). 
FIGURE 10 Changes in relative probability of dying (\%) between the underprivileged and privileged social groups (privileged SG = index of 100)
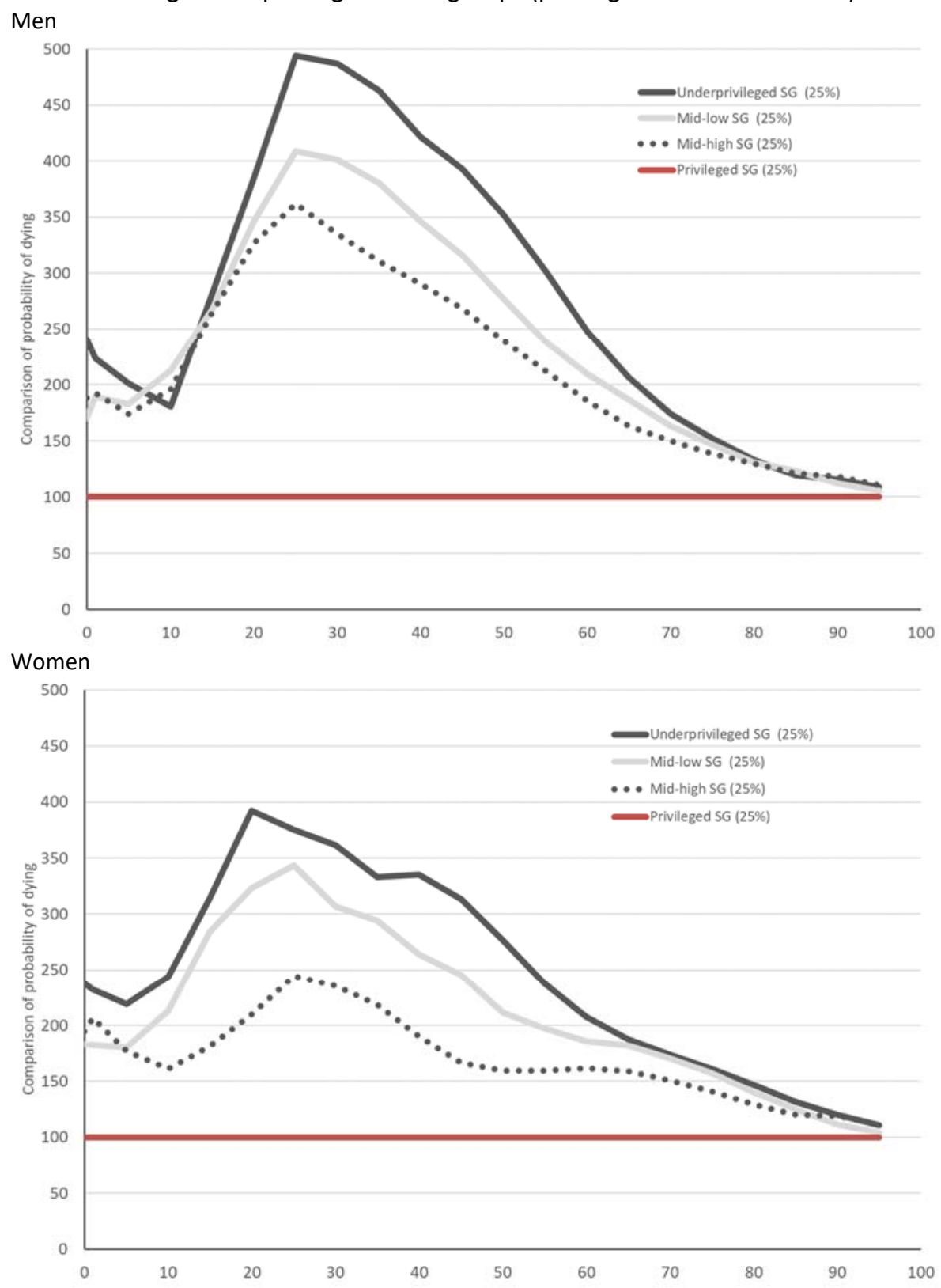

Sources: National Register, censuses. 
Therefore it can be considered that the greater the impact of the older ages on improvements in life expectancy, the further down the road the social group has travelled in terms of the health transition. As well, a significant impact from children and adults signals a delay. In this context the privileged group is undeniably at the forefront of the health transition while the underprivileged group is well behind (Table 4). Over two decades, declining mortality for privileged men over 60 years old has translated into a gain in life expectancy of 3.2 years, while for those in the least privileged quartile and those among the $5 \%$ least privileged the gain has been 1.9 years and 1 year, respectively. Alongside this, for these two groups the impact of men under 40 years old is significant: 1.5 years for the lowest quartile and 2.3 years for the $5 \%$ least privileged, while for the most privileged the gain is only 0.9 years. For the least privileged (5\%), weak gains in life expectancy for those over 60 years old, and especially over 80, point to this group's delay in the health transition and its high vulnerability (to cardiovascular diseases and other pathologies particularly affecting older people ( $c f$. section 2.5 ).

TABLE 4 Impact of age groups on improvements in life expectancy between 1992-1996 and 2011-2015 according to social group

\begin{tabular}{|l|l|l|l|l|l|l|}
\hline Ages & Total & $\begin{array}{c}\text { Underprivi- } \\
\text { leged (5\%) }\end{array}$ & $\begin{array}{c}\text { Underprivi- } \\
\text { leged (25\%) }\end{array}$ & Mid-low & Mid-high & Privileged \\
\hline Men & & & & & & \\
\hline $0-19$ & 0.6 & 0.8 & 0.7 & 0.4 & 0.4 & 0.5 \\
\hline $20-39$ & 0.5 & 1.5 & 0.8 & 0.6 & 0.6 & 0.4 \\
\hline $40-59$ & 0.9 & 1.3 & 0.8 & 0.8 & 0.9 & 0.9 \\
\hline $60-79$ & 2.2 & 0.9 & 1.5 & 2.1 & 2.0 & 2.4 \\
\hline $80+$ & 0.6 & 0.1 & 0.4 & 0.7 & 0.6 & 0.8 \\
\hline Gains E0 & 4.8 & 4.6 & 4.3 & 4.6 & 4.6 & 5.1 \\
\hline Women & & & & & 0.2 & 0.3 \\
\hline $0-19$ & 0.4 & 0.4 & 0.4 & 0.2 & 0.2 & 0.3 \\
\hline $20-39$ & 0.2 & 0.2 & 0.2 & 0.2 & 0.4 & 0.7 \\
\hline $40-59$ & 0.4 & 0.3 & -0.1 & 0.3 & 1.2 & 1.4 \\
\hline $60-79$ & 1.2 & 0.3 & 1.0 & 1.2 & 0.9 & 1.3 \\
\hline $80+$ & 0.8 & 0.0 & 0.6 & 1.1 & 3.9 \\
\hline Gains E0 & 3.0 & 1.3 & 2.1 & 3.0 & 2.6 & 3.9 \\
\hline
\end{tabular}

Sources: National Register, censuses; authors' calculations. 


\section{Social inequalities in mortality according to cause of death}

The most underprivileged social groups have higher mortality than do the more privileged groups for most causes of death. In European countries the social differences in terms of risk of death are generally attributable to the same diseases: cardiovascular disease, cancer, and digestive and respiratory diseases (Cambois, Jusot, 2007). Many factors have been proposed to explain these differences in mortality by social group (Mackenbach et al., 2008). First, certain high-risk behaviours are more prevalent and cumulative among the least privileged groups, such as smoking, excessive consumption of alcohol and poor-quality foods, and an excessively sedentary lifestyle (lack or insufficient levels of physical activity). In Belgium social inequalities in mortality mostly involve cirrhosis of the liver, lung cancer, and cardiovascular disease (Gadeyne, 2006; Willems et al., 2007). Second, social disparities in mortality are also linked to diseases in which prevention plays an important role (e.g., bowel cancer, breast cancer, suicide). In Belgium, as in other European countries, diagnosis is generally earlier among the more privileged social classes because they are more receptive to prevention campaigns and are more systematic users of general and specialized health care services (Cambois, Jusot, 2007; Willems et al., 2007). Third, the physical and social environment also has an impact on the maintenance of social inequalities in mortality, in a context of strong social polarization of residential areas. Independently of the individual characteristics of their inhabitants, underprivileged districts are less conducive to the health of their inhabitants, for example having less green space, poorer health infrastructure, and greater exposure to noise and air pollution (Willems et al., 2007).

Tables 5 and 6 show, for the observation periods 1992-1996, 2002-2006 and 2011-2015 and for the four social groups defined above, the probability of dying and ratios between the probability of dying for the main causes of death - tumours, circulatory diseases, respiratory diseases, external causes, and other causes ${ }^{16}$.

\footnotetext{
16. These categories were defined according to the Ninth Revision of the World Health Organization's International Classification of Diseases (ICD-9) for 1992-1996 and the Tenth Revision (ICD-10) for 1998 and later.
} 
TABLE 5 The probability of dying for men, by cause of death and social group in Belgium

\begin{tabular}{|c|c|c|c|c|c|c|c|c|c|c|c|c|c|}
\hline \multirow{2}{*}{ Cause of death } & \multirow{2}{*}{ Ages } & \multicolumn{4}{|c|}{$1992-1996$} & \multicolumn{4}{|c|}{$2002-2006$} & \multicolumn{4}{|c|}{$2011-2015$} \\
\hline & & Q1 & Q2 & Q3 & Q4 & Q1 & Q2 & Q3 & Q4 & Q1 & Q2 & Q3 & Q4 \\
\hline \multicolumn{14}{|l|}{ Tumour } \\
\hline \multirow{4}{*}{ Probabilities (\%o) } & $20-39$ & 3 & 3 & 2 & 2 & 3 & 2 & 2 & 1 & 3 & 2 & 2 & 1 \\
\hline & $40-64$ & 96 & 74 & 61 & 48 & 89 & 60 & 49 & 38 & 80 & 53 & 40 & 29 \\
\hline & $65-79$ & 230 & 208 & 188 & 161 & 200 & 167 & 154 & 129 & 181 & 154 & 141 & 108 \\
\hline & $80-94$ & 447 & 423 & 394 & 342 & 416 & 384 & 356 & 318 & 375 & 345 & 328 & 309 \\
\hline \multirow{4}{*}{ Probability ratio } & $20-39$ & 1,76 & 1,29 & 1,21 & 1,00 & 2,56 & 1,60 & 1,38 & 1,00 & 2,42 & 1,69 & 1,40 & 1,00 \\
\hline & $40-64$ & 2,02 & 1,56 & 1,27 & 1,00 & 2,33 & 1,57 & 1,29 & 1,00 & 2,78 & 1,84 & 1,40 & 1,00 \\
\hline & $65-79$ & 1,43 & 1,29 & 1,17 & 1,00 & 1,55 & 1,30 & 1,19 & 1,00 & 1,67 & 1,43 & 1,30 & 1,00 \\
\hline & $80-94$ & 1,31 & 1,24 & 1,15 & 1,00 & 1,31 & 1,21 & 1,12 & 1,00 & 1,21 & 1,12 & 1,06 & 1,00 \\
\hline \multicolumn{14}{|l|}{ Circulatory } \\
\hline \multirow{4}{*}{ Probabilities (\%o) } & $20-39$ & 4 & 2 & 2 & 1 & 3 & 2 & 1 & 1 & 2 & 1 & 1 & 1 \\
\hline & $40-64$ & 73 & 48 & 39 & 30 & 62 & 35 & 29 & 21 & 47 & 27 & 19 & 12 \\
\hline & $65-79$ & 241 & 214 & 192 & 158 & 189 & 140 & 128 & 104 & 130 & 104 & 93 & 60 \\
\hline & $80-94$ & 705 & 676 & 662 & 587 & 669 & 618 & 587 & 554 & 568 & 510 & 503 & 439 \\
\hline \multirow{4}{*}{ Probability ratio } & $20-39$ & 3,69 & 2,09 & 1,56 & 1,00 & 3,91 & 2,28 & 1,60 & 1,00 & 3,77 & 1,96 & 1,61 & 1,00 \\
\hline & $40-64$ & 2,43 & 1,61 & 1,32 & 1,00 & 2,94 & 1,68 & 1,38 & 1,00 & 3,84 & 2,21 & 1,59 & 1,00 \\
\hline & $65-79$ & 1,53 & 1,35 & 1,21 & 1,00 & 1,82 & 1,35 & 1,24 & 1,00 & 2,18 & 1,74 & 1,55 & 1,00 \\
\hline & $80-94$ & 1,20 & 1,15 & 1,13 & 1,00 & 1,21 & 1,12 & 1,06 & 1,00 & 1,30 & 1,16 & 1,15 & 1,00 \\
\hline \multicolumn{14}{|l|}{ Respiratory } \\
\hline \multirow{4}{*}{ Probabilities (\%o) } & $20-39$ & 1 & 0 & 0 & 0 & 1 & 0 & 0 & 0 & 0 & 0 & 0 & 4 \\
\hline & $40-64$ & 22 & 10 & 6 & 3 & 19 & 7 & 4 & 3 & 18 & 7 & 4 & 2 \\
\hline & $65-79$ & 108 & 75 & 56 & 36 & 93 & 55 & 43 & 31 & 67 & 41 & 35 & 21 \\
\hline & $80-94$ & 394 & 299 & 271 & 184 & 420 & 326 & 300 & 249 & 323 & 246 & 251 & 195 \\
\hline \multirow{4}{*}{ Probability ratio } & $20-39$ & 5,50 & 2,65 & 2,22 & 1,00 & 12,73 & 4,98 & 2,81 & 1,00 & 0,11 & 0,06 & 0,03 & 1,00 \\
\hline & $40-64$ & 7,21 & 3,13 & 1,84 & 1,00 & 6,42 & 2,50 & 1,42 & 1,00 & 8,22 & 3,12 & 1,85 & 1,00 \\
\hline & $65-79$ & 3,02 & 2,10 & 1,55 & 1,00 & 3,03 & 1,80 & 1,39 & 1,00 & 3,22 & 1,95 & 1,70 & 1,00 \\
\hline & $80-94$ & 2,14 & 1,63 & 1,48 & 1,00 & 1,69 & 1,31 & 1,20 & 1,00 & 1,66 & 1,26 & 1,29 & 1,00 \\
\hline \multicolumn{14}{|l|}{ External } \\
\hline \multirow{4}{*}{ Probabilities (\%o) } & $20-39$ & 28 & 19 & 16 & 9 & 22 & 16 & 12 & 7 & 17 & 12 & 8 & 5 \\
\hline & $40-64$ & 29 & 20 & 17 & 13 & 25 & 18 & 15 & 11 & 27 & 19 & 14 & 10 \\
\hline & $65-79$ & 24 & 19 & 17 & 14 & 19 & 13 & 11 & 10 & 17 & 15 & 13 & 9 \\
\hline & $80-94$ & 91 & 91 & 59 & 53 & 72 & 65 & 49 & 49 & 69 & 62 & 60 & 52 \\
\hline \multirow{4}{*}{ Probability ratio } & $20-39$ & 3,06 & 2,12 & 1,75 & 1,00 & 3,10 & 2,31 & 1,74 & 1,00 & 3,71 & 2,60 & 1,72 & 1,00 \\
\hline & $40-64$ & 2,21 & 1,54 & 1,30 & 1,00 & 2,22 & 1,64 & 1,35 & 1,00 & 2,72 & 1,93 & 1,41 & 1,00 \\
\hline & $65-79$ & 1,73 & 1,39 & 1,21 & 1,00 & 1,89 & 1,32 & 1,11 & 1,00 & 1,98 & 1,67 & 1,50 & 1,00 \\
\hline & $80-94$ & 1,72 & 1,71 & 1,11 & 1,00 & 1,48 & 1,34 & 1,00 & 1,00 & 1,32 & 1,19 & 1,15 & 1,00 \\
\hline \multicolumn{14}{|l|}{ Other } \\
\hline \multirow{4}{*}{ Probabilities (\%o) } & $20-39$ & 9 & 4 & 3 & 2 & 9 & 4 & 2 & 1 & 7 & 3 & 2 & 1 \\
\hline & $40-64$ & 48 & 26 & 20 & 15 & 54 & 25 & 22 & 15 & 67 & 34 & 25 & 15 \\
\hline & $65-79$ & 103 & 82 & 75 & 63 & 101 & 70 & 67 & 55 & 116 & 85 & 81 & 61 \\
\hline & $80-94$ & 459 & 426 & 407 & 358 & 454 & 388 & 395 & 348 & 505 & 442 & 451 & 394 \\
\hline & $20-39$ & 4,99 & 2,12 & 1,47 & 1,00 & 9,65 & 3,84 & 1,80 & 1,00 & 6,75 & 3,10 & 2,10 & 1,00 \\
\hline & $40-64$ & 3,19 & 1,70 & 1,31 & 1,00 & 3,67 & 1,70 & 1,47 & 1,00 & 4,41 & 2,27 & 1,62 & 1,00 \\
\hline Prob & $65-79$ & 1,63 & 1,30 & 1,18 & 1,00 & 1,82 & 1,27 & 1,21 & 1,00 & 1,91 & 1,39 & 1,34 & 1,00 \\
\hline & $80-94$ & 1,28 & 1,19 & 1,14 & 1,00 & 1,31 & 1,11 & 1,14 & 1,00 & 1,28 & 1,12 & 1,14 & 1,00 \\
\hline
\end{tabular}

Sources: National Register, censuses, official death registry; authors' calculations. 
TABLE 6 The probability of dying for women, by cause of death and social group in Belgium

\begin{tabular}{|c|c|c|c|c|c|c|c|c|c|c|c|c|c|}
\hline \multirow{2}{*}{ Cause of death } & \multirow{2}{*}{ Ages } & \multicolumn{4}{|c|}{$1992-1996$} & \multicolumn{4}{|c|}{$2002-2006$} & \multicolumn{4}{|c|}{ 2011-2015 } \\
\hline & & Q1 & Q2 & Q3 & Q4 & Q1 & Q2 & Q3 & Q4 & Q1 & Q2 & Q3 & Q4 \\
\hline \multicolumn{14}{|l|}{ Tumour } \\
\hline \multirow{4}{*}{ Probabilities (\%o) } & $20-39$ & 3 & 3 & 3 & 2 & 4 & 2 & 2 & 2 & 3 & 2 & 2 & 2 \\
\hline & $40-64$ & 50 & 46 & 42 & 44 & 51 & 40 & 36 & 34 & 53 & 40 & 32 & 28 \\
\hline & $65-79$ & 101 & 90 & 90 & 88 & 94 & 82 & 82 & 75 & 94 & 82 & 81 & 73 \\
\hline & $80-94$ & 233 & 212 & 200 & 205 & 215 & 201 & 209 & 210 & 210 & 195 & 197 & 184 \\
\hline \multirow{4}{*}{ Probability ratio } & $20-39$ & 1,39 & 1,21 & 1,01 & 1,00 & 1,90 & 1,30 & 1,25 & 1,00 & 1,71 & 1,26 & 1,08 & 1,00 \\
\hline & $40-64$ & 1,14 & 1,05 & 0,95 & 1,00 & 1,52 & 1,19 & 1,08 & 1,00 & 1,89 & 1,41 & 1,15 & 1,00 \\
\hline & $65-79$ & 1,15 & 1,02 & 1,02 & 1,00 & 1,27 & 1,10 & 1,10 & 1,00 & 1,30 & 1,13 & 1,12 & 1,00 \\
\hline & $80-94$ & 1,14 & 1,03 & 0,97 & 1,00 & 1,02 & 0,96 & 1,00 & 1,00 & 1,14 & 1,06 & 1,07 & 1,00 \\
\hline \multicolumn{14}{|l|}{ Circulatory } \\
\hline \multirow{4}{*}{ Probabilities (\%o) } & $20-39$ & 2 & 1 & 1 & 1 & 2 & 1 & 1 & 0 & 1 & 1 & 1 & 0 \\
\hline & $40-64$ & 26 & 15 & 11 & 9 & 25 & 13 & 10 & 6 & 21 & 10 & 7 & 4 \\
\hline & $65-79$ & 150 & 114 & 91 & 77 & 108 & 71 & 58 & 47 & 73 & 49 & 46 & 30 \\
\hline & $80-94$ & 653 & 595 & 567 & 510 & 598 & 518 & 486 & 443 & 507 & 410 & 417 & 354 \\
\hline \multirow{4}{*}{ Probability ratio } & $20-39$ & 3,88 & 2,42 & 1,67 & 1,00 & 4,28 & 2,48 & 1,67 & 1,00 & 6,20 & 4,24 & 3,26 & 1,00 \\
\hline & $40-64$ & 3,03 & 1,78 & 1,33 & 1,00 & 3,87 & 2,08 & 1,57 & 1,00 & 5,14 & 2,46 & 1,77 & 1,00 \\
\hline & $65-79$ & 1,94 & 1,48 & 1,17 & 1,00 & 2,31 & 1,52 & 1,24 & 1,00 & 2,46 & 1,66 & 1,56 & 1,00 \\
\hline & $80-94$ & 1,28 & 1,17 & 1,11 & 1,00 & 1,35 & 1,17 & 1,10 & 1,00 & 1,43 & 1,16 & 1,18 & 1,00 \\
\hline \multicolumn{14}{|l|}{ Respiratory } \\
\hline \multirow{4}{*}{ Probabilities (\%o) } & $20-39$ & 1 & 0 & 0 & 0 & 1 & 0 & 0 & 0 & 0 & 0 & 2 & 1 \\
\hline & $40-64$ & 7 & 3 & 2 & 1 & 9 & 3 & 2 & 2 & 11 & 4 & 2 & 1 \\
\hline & $65-79$ & 28 & 18 & 16 & 14 & 32 & 18 & 15 & 13 & 29 & 18 & 14 & 10 \\
\hline & $80-94$ & 177 & 145 & 131 & 119 & 219 & 158 & 160 & 140 & 178 & 131 & 125 & 98 \\
\hline \multirow{4}{*}{ Probability ratio } & $20-39$ & 13,99 & 5,47 & 5,40 & 1,00 & 10,65 & 3,88 & 1,95 & 1,00 & 0,38 & 0,16 & 1,69 & 1,00 \\
\hline & $40-64$ & 5,47 & 2,68 & 1,86 & 1,00 & 5,75 & 2,07 & 1,48 & 1,00 & 9,90 & 4,06 & 2,07 & 1,00 \\
\hline & $65-79$ & 2,00 & 1,32 & 1,12 & 1,00 & 2,44 & 1,39 & 1,19 & 1,00 & 2,83 & 1,73 & 1,42 & 1,00 \\
\hline & $80-94$ & 1,49 & 1,22 & 1,10 & 1,00 & 1,56 & 1,13 & 1,14 & 1,00 & 1,83 & 1,34 & 1,28 & 1,00 \\
\hline \multicolumn{14}{|l|}{ External } \\
\hline \multirow{4}{*}{ Probabilities (\%o) } & $20-39$ & 7 & 5 & 4 & 4 & 6 & 4 & 3 & 2 & 5 & 3 & 3 & 1 \\
\hline & $40-64$ & 10 & 8 & 7 & 8 & 9 & 7 & 7 & 6 & 11 & 8 & 6 & 5 \\
\hline & $65-79$ & 12 & 10 & 8 & 8 & 9 & 8 & 7 & 5 & 9 & 7 & 7 & 5 \\
\hline & $80-94$ & 58 & 52 & 51 & 47 & 46 & 42 & 44 & 38 & 48 & 39 & 41 & 36 \\
\hline \multirow{4}{*}{ Probability ratio } & $20-39$ & 1,95 & 1,41 & 1,14 & 1,00 & 2,55 & 1,84 & 1,53 & 1,00 & 3,93 & 2,74 & 2,03 & 1,00 \\
\hline & $40-64$ & 1,36 & 1,03 & 0,96 & 1,00 & 1,65 & 1,17 & 1,14 & 1,00 & 2,13 & 1,53 & 1,25 & 1,00 \\
\hline & $65-79$ & 1,52 & 1,29 & 1,05 & 1,00 & 1,73 & 1,50 & 1,43 & 1,00 & 1,64 & 1,29 & 1,34 & 1,00 \\
\hline & $80-94$ & 1,23 & 1,11 & 1,09 & 1,00 & 1,19 & 1,09 & 1,15 & 1,00 & 1,33 & 1,09 & 1,13 & 1,00 \\
\hline \multicolumn{14}{|l|}{ Other } \\
\hline \multirow{4}{*}{ Probabilities (\%o) } & $20-39$ & 4 & 2 & 1 & 1 & 5 & 2 & 1 & 1 & 4 & 2 & 2 & 1 \\
\hline & $40-64$ & 23 & 13 & 11 & 8 & 26 & 14 & 11 & 7 & 33 & 18 & 12 & 8 \\
\hline & $65-79$ & 77 & 56 & 49 & 43 & 74 & 47 & 40 & 35 & 79 & 52 & 51 & 36 \\
\hline & $80-94$ & 443 & 382 & 360 & 340 & 432 & 338 & 306 & 289 & 492 & 371 & 388 & 340 \\
\hline & $20-39$ & 3,89 & 2,34 & 1,40 & 1,00 & 9,06 & 3,28 & 1,88 & 1,00 & 6,83 & 3,85 & 2,43 & 1,00 \\
\hline Probability & $40-64$ & 2,97 & 1,68 & 1,45 & 1,00 & 3,50 & 1,87 & 1,50 & 1,00 & 3,99 & 2,21 & 1,51 & 1,00 \\
\hline Prodability ratio & $65-79$ & 1,81 & 1,32 & 1,15 & 1,00 & 2,11 & 1,34 & 1,15 & 1,00 & 2,18 & 1,45 & 1,42 & 1,00 \\
\hline & $80-94$ & 1,30 & 1,12 & 1,06 & 1,00 & 1,49 & 1,17 & 1,06 & 1,00 & 1,45 & 1,09 & 1,14 & 1,00 \\
\hline
\end{tabular}

Sources: National Register, censuses, official death register; authors' calculations.

For 2011-2015, the greatest risk of dying for the 40-64 years age group was posed by tumours, for both sexes and across social groups. Between 65 and 79 years, for all social groups, tumours remained the main cause 
of death for men and women. Finally, for 80-94-year-olds the greatest risk of dying lay in circulatory diseases, for both sexes and all social groups. Beyond this identical structure for cause of death by social group for both periods of observation other conclusions can be drawn. First, for each cause of death and for each age group, the risk of death changes according to social gradient: the higher up the social ladder, the lower the risk of dying. This applies to both sexes and for both periods of observation.

Second, the extent of the differences between social groups varies according to age, sex, and cause of death. Thus for each cause of death, the risk ratio - which measures the extent of inequalities in relation to the privileged social group - generally decreases with age. Taking the example of mortality by circulatory disease for men in the period 2011-2015, we find that at 40-64 years old, the risk of dying for the underprivileged social group is 3.8 times higher than it is for the privileged social group. At 6579 years, the risk ratio is 2.2 , and at $80-94$ years, 1.3 . Social inequalities in mortality, while not dissipating completely, weaken with age, thus at least partially confirming the hypothesis of a selection effect whereby those that are weaker are progressively removed (Oris, Lerch, 2009), unless exposure during working age to these diseases is subject to a strong social differentiation (e.g., in the professional realm) to become more egalitarian afterwards.

Diseases of the respiratory system 17 are the cause of death for which social inequalities are highest, for all age groups and for both sexes. Next come diseases of the circulatory system and other causes of death. Except the diseases of the circulatory system, differences between social groups are higher for men than for women.

And finally, between the periods of observation 1992-1996 and 20112015 , social inequalities in mortality by cause of death have increased for most age groups, for women and men alike. This is especially true for mortality by circulatory disease and tumour.

17. Chronic obstructive pulmonary disease is one of the main causes of death linked to respiratory disease. 


\section{Spatial inequalities in mortality: A persistent trend}

\section{Regional and sub-regional approaches}

For at least two centuries there has been a regional contrast between Flanders (in the north of the country) and Wallonia (in the south) in terms of mortality. In the nineteenth century in Flanders mortality was decidedly higher for both women and men than in Wallonia (Figure 11). In the middle and at the end of the century the difference in life expectancy between the two regions was a little over four years (Table 7).

\section{FIGURE 11 Changes in life expectancy at birth according to sex} in Flanders and Wallonia

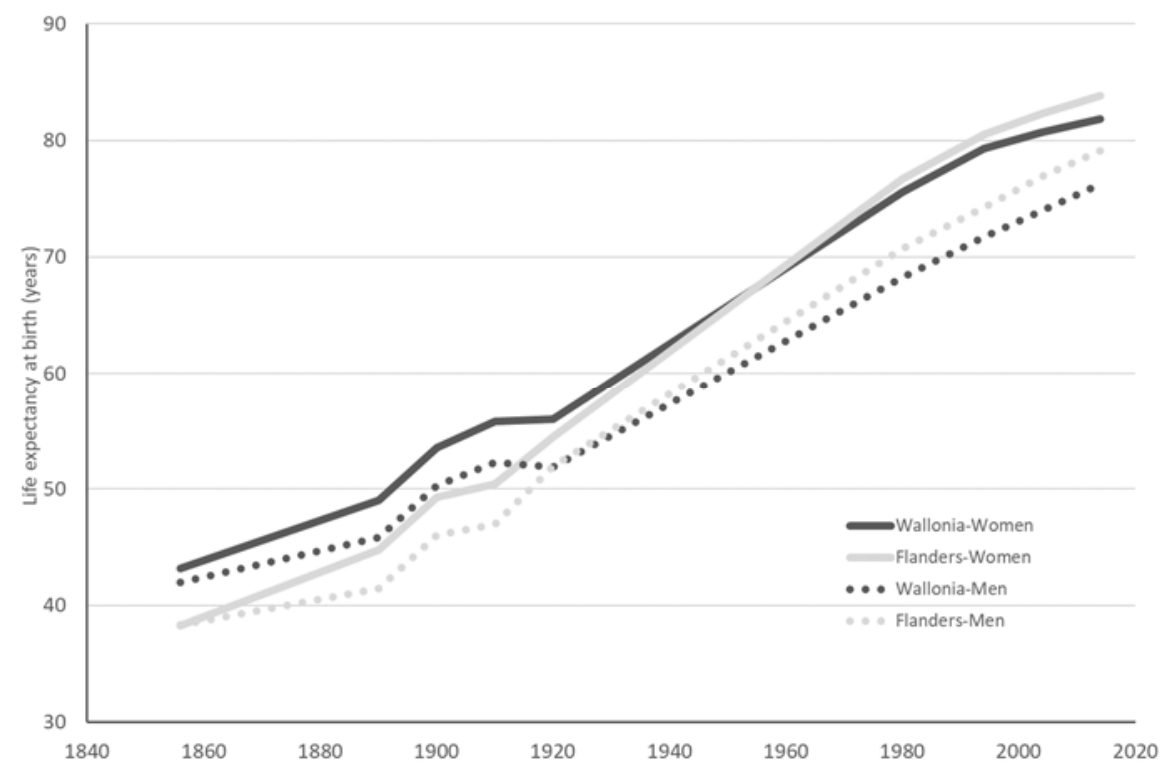

The differences in mortality between the two regions are manifestations of profound inequalities in terms of standard of living: in Wallonia industrial and economic development took place earlier, while in Flanders the population was impoverished due to economic and social underdevelopment. There were also regional differences in infant feeding and childrearing practices, mothers' educational level, water quality and other factors (Masuy-Stroobant, 1983). During this period, it was young children that were most affected by regional inequalities in mortality. In 1890 the probability of infant mortality was $190 \%$ in the north of the 
country while in Wallonia it was $140 \%$ (Eggerickx et al., 2012). At the start of the twentieth century, the difference in life expectancy between the two main linguistic regions can be almost completely explained by relative low mortality for those under 15 years old in Wallonia, and especially for children under 1 year old. Conversely, for men over 15 years of age, life expectancy in Wallonia fell to 0.5 years below that of Flanders, a trend that strengthened and spread to women over 15 years of age after the First World War (Table 7).

TABLE 7 Breakdown by age group of differences in life expectancy at birth between Wallonia and Flanders

\begin{tabular}{|l|c|c|c|c|c|c|c|c|c|c|}
\hline & \multicolumn{3}{|c}{$1855-1857$} & \multicolumn{3}{c|}{$1898-1903$} & \multicolumn{3}{c|}{$1919-1922$} \\
\hline & Total & Men & Women & Total & Men & Women & Total & Men & Women \\
\hline $0-1$ & 1.6 & 1.5 & 1.7 & 3.4 & 3.6 & 3.2 & 1.7 & 1.6 & 1.7 \\
\hline $1-14$ & 1.9 & 1.8 & 2.0 & 1.3 & 1.3 & 1.3 & 0.7 & 0.7 & 0.7 \\
\hline $15-29$ & 0.0 & -0.2 & 0.3 & -0.2 & -0.1 & -0.3 & -0.6 & -0.6 & -0.5 \\
\hline $30-59$ & 0.5 & 0.4 & 0.7 & 0.0 & -0.1 & 0.2 & -0.6 & -1.0 & -0.2 \\
\hline$>60$ & 0.2 & 0.1 & 0.2 & -0.2 & -0.3 & 0.0 & -0.4 & -0.6 & -0.2 \\
\hline Total & 4.3 & 3.7 & 5.0 & 4.4 & 4.4 & 4.4 & 0.8 & 0.1 & 1.6 \\
\hline
\end{tabular}

Source: authors' calculations ${ }^{18}$.

From that period, the levels of life expectancy at birth between Flanders and Wallonia began to undergo a progressive reversal, first for men and then for women (Figure 12). This reversal did not take place at the same time for all the ages: it happened among older people first and later among the young (Grimmeau et al., 2010). From the early 1960s excess mortality in Wallonia became generalized and remains the case today. The groups most affected by this regional disparity in mortality are adults 30-65 years old, young people 10-19 years, and men more generally ${ }^{19}$. Mortality tables for 2011-2015 show that male life expectancy at birth was 79.1 years in Flanders and 76.2 years in Wallonia, while for women these figures were 83.8 years and 81.8 years respectively. While for men the difference has been stable at less than 3 years for two decades, for women it has widened, from 1.2 years in 1992-1996 to 2 years in 20112015. The most common hypotheses to explain these regional inequali-

18. Based on data from population censuses for 1856, 1900 and on statistics on «Mouvement de la population et de l'état-civil» for the surrounding years.

19. It is worth noting that adult men had already been identified as the main casualties of this excess mortality in Wallonia in the 1960s (Van Houte, Wunsch, 1978). 
ties include socioeconomic differences between «rich» Flanders «impoverished» Wallonia and sociocultural differences in nutritional practices, tobacco and alcohol consumption, etc. (Deboosere, Gadeyne, 2002).

At a smaller geographic scale - that of administrative districts - differences in mortality were particularly pronounced in the nineteenth and early twentieth centuries. Around 1900, male life expectancy at birth was 15 years higher in the Walloon district of Philippeville (55.4 years) than in the Flemish district of Ostend (40.8 years) (Eggerickx et al., 2012). For women in these same districts, the disparity was 11 years (56.5 years in Philippeville and 45.1 years in Ostend).

While at the start of the twentieth century the highest life expectancies were to be found in Wallonia and the lowest ones in Flanders, the maps in Figure 13 for 1897-1903 reveal that there are nuances within this simplified and dualistic picture of Belgium. The overall contrast between the two regions is less pronounced today and many Flemish districts have life expectancies similar to those of Walloon districts. In addition, T. Van Rossem (2018) demonstrated that at that time, the spatial pattern of mortality by district varied greatly according to age, sex and cause of death. Thus, a clear line between the two regions can only be drawn for the mortality of children under 7 years of age, with excess mortality in Flanders and undermortality in Wallonia. This regional duality does not apply for adolescent and adult mortality or for causes.

In a little over a century, the spatial pattern of mortality has completely reversed, with undermortality in the Flemish districts and excess mortality in the Walloon districts, with the exception of the suburban district of Nivelles south of Brussels (Figure 12). Disparities between districts are less significant than at the beginning of the twentieth century; in 20112015 , the difference is just under 6 years for men and almost 4 years for women. Nevertheless, like social inequalities, spatial differences in mortality have increased since the early 1990s (from a gap of 4.7 years in 1992-1996 to 5.7 years in 2011-2015 for men and from 2.7 to 3.6 years for women between the same periods).

Older studies have shown that in Belgium there was a trend toward spatial uniformity (reductions) in mortality levels between 1970 and the start of the 1990s (Duchêne, Thiltgès, 1993), which has since been followed by an increase in inequalities between districts, for both men and women (Table 8). It should be noted that in France, differences in mortality between departments narrowed for men until the early 1990s and for women until the early 2000s, before also increasing (Barbieri, 2013). 
FIGURE 12 Life expectancy at birth according to sex and period 1897-1903

Men

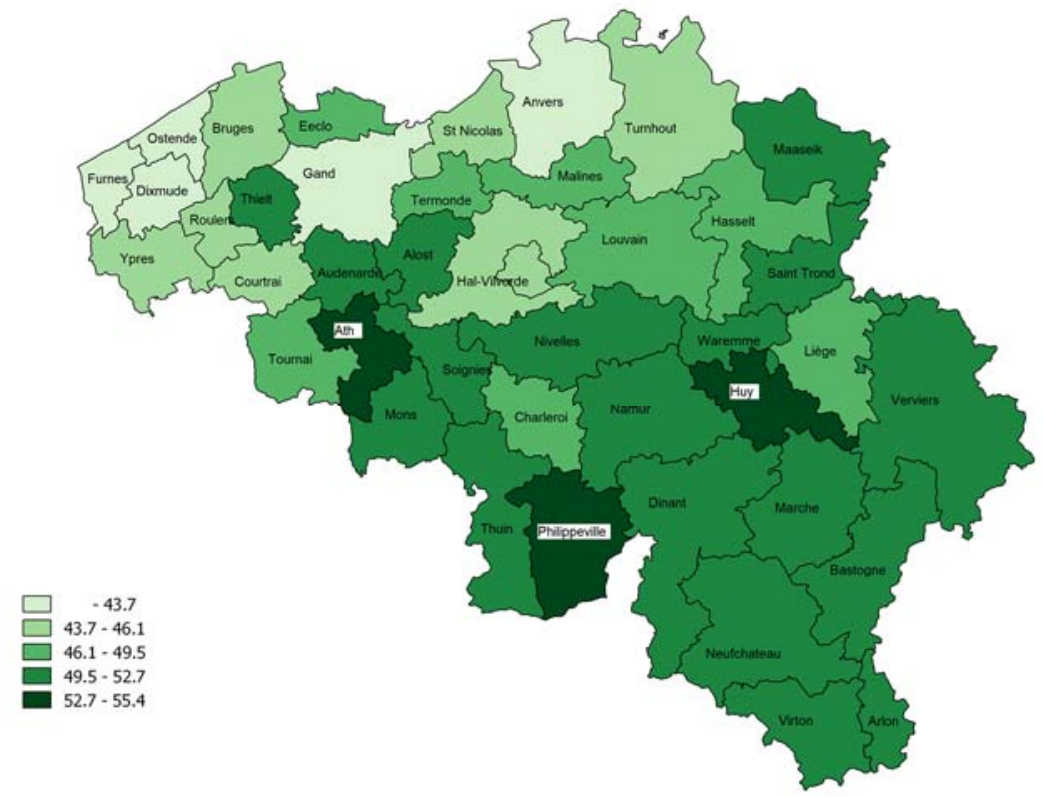

Women

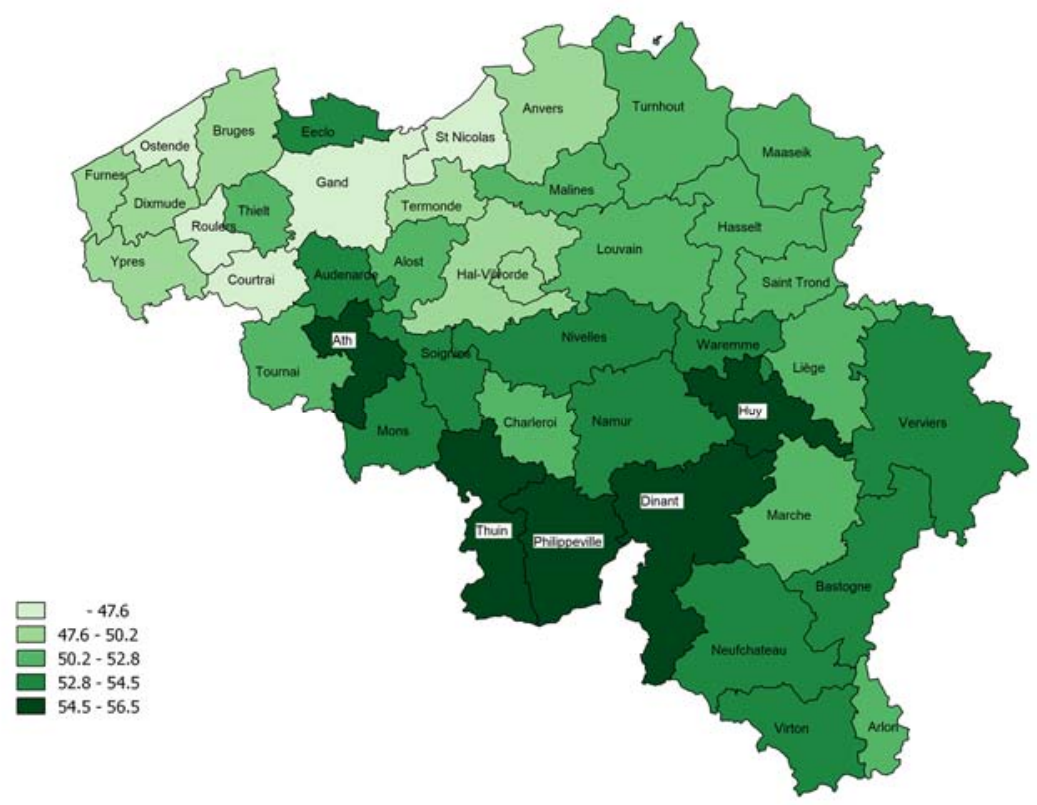


Men

2011-2015

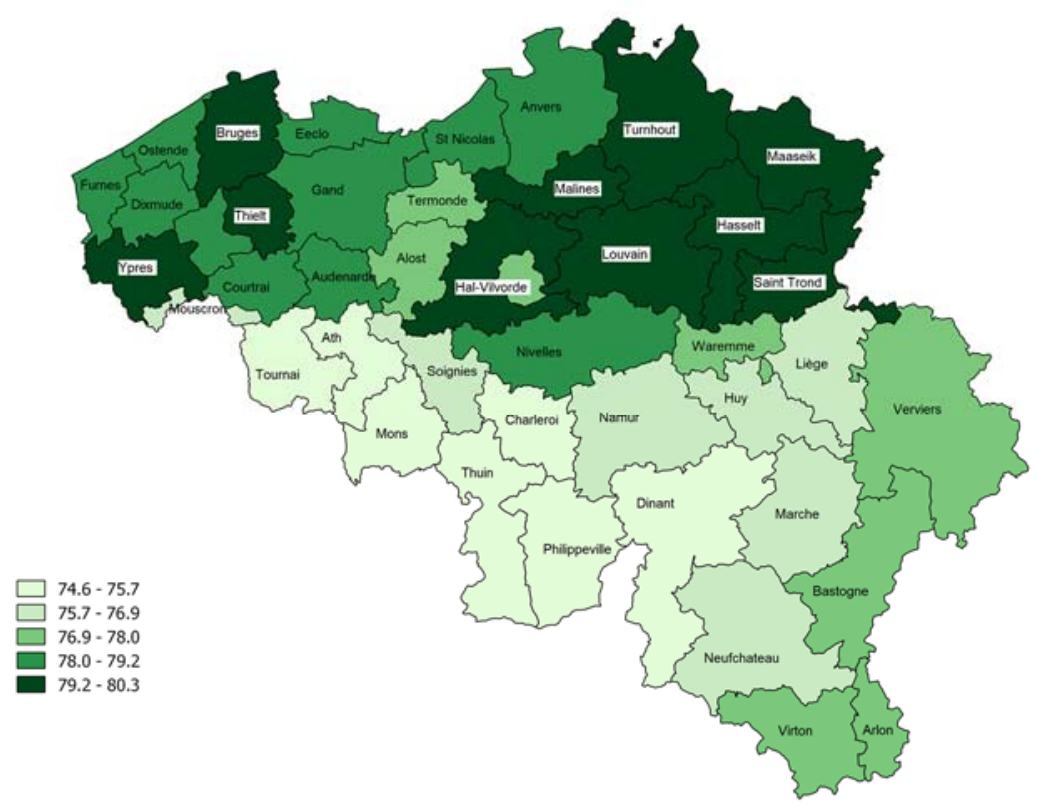

Women

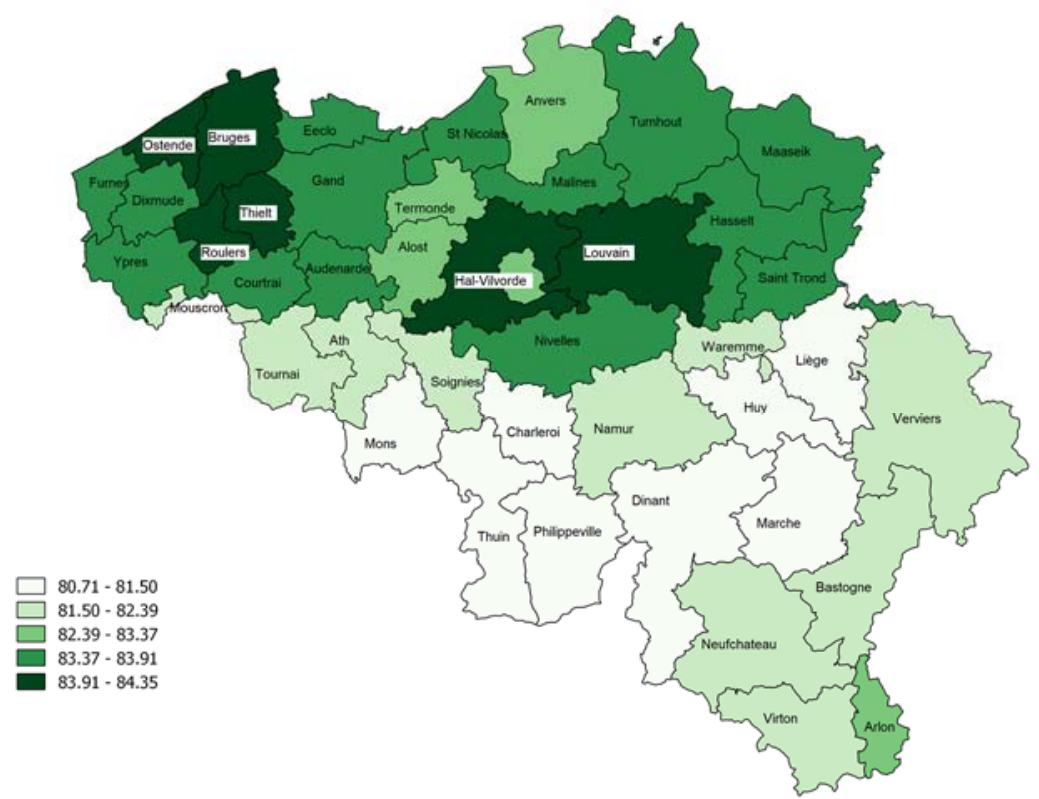


There is no doubt about the relationship between life expectancy at birth and the socioeconomic characteristics of the district population (Duchêne, Thiltgès, 1993; Deboosere, Gadeyne, 2002). Overall, districts characterized by low median declared income (2015) are also characterized by low life expectancy at birth, and vice versa (Eggerickx et al., 2018b).

TABLE 8 Evolution of selected indexes of differences in mortality at the district level

\begin{tabular}{|l|c|c|c|c|c|c|c|c|} 
& \multicolumn{2}{|c|}{$1979-1983$} & \multicolumn{2}{c|}{$1992-1996$} & \multicolumn{2}{c|}{ 2002-2006 } & \multicolumn{2}{c|}{ 2011-2015 } \\
\cline { 2 - 11 } & Men & Women & Men & Women & Men & Women & Men & Women \\
\hline Minimum & 66.9 & 74.5 & 70.3 & 78.4 & 72.2 & 79.9 & 74.6 & 80.7 \\
\hline Maximum & 71.8 & 77.5 & 75.0 & 81.2 & 77.5 & 82.8 & 80.3 & 84.4 \\
\hline Difference & 4.9 & 3.0 & 4.7 & 2.7 & 5.3 & 2.9 & 5.7 & 3.7 \\
\hline Standard Deviation & 1.43 & 0.75 & 1.42 & 0.70 & 1.59 & 0.92 & 1.62 & 1.08 \\
\hline
\end{tabular}

The mapping of causes of death at the district level 20 , on the one hand, tempers for some of them the regional dualism of mortality, and on the other hand, invites to consider explanatory factors complementary to the socio-economic composition of the populations to explain the mortality differential(s) (Grimmeau et al., 2015). In 1991-1995, cardiovascular disease was the leading cause of death for both men and women and accounted for a large part of the differences between Flanders and Wallonia. There is a high correlation between cardiovascular disease and socioeconomic status, but other elements are also at play, such as genetic factors and sociocultural behaviours associated with tobacco and alcohol consumption, physical exercise, and eating habits. Strong regional contrasts are found for other causes of death, with a higher prevalence in the country's south: these include alcohol-related deaths, male suicide, and road accidents, which can be correlated with the configuration and quality of the road network or the density and proximity of emergency medical services. Finally, while there is an east-west divide for lung cancer mortality, no regional pattern can be discerned in breast cancer mortality for women or prostate cancer mortality for men (Grimmeau et al., 2015). These results are largely confirmed by Renard et al. (2017) in their study conducted on premature mortality by cause of death at the district level during 2003-2009.

20. Mapping was done for the observation period 1991-1995 and would need updating. 


\section{By place of residence}

Urban excess mortality is a recurring feature of eighteenth- and nineteenth-century demographics, and growing urbanization, which at least initially was associated with deteriorating housing conditions and public and private hygiene, very probably contributed to widening gaps between place of residence (Eggerickx, Debuisson, 1990; Oris, Ramino Farinas, 2016). In his Mémoire sur les lois des naissances et de la mortalité à Bruxelles, A. Quetelet noted the «tremendous difference» in mortality between the city and the countryside in the early nineteenth century. In 1855-1857, life expectancy at birth in the city of Brussels was 30.6 years but 39.7 years in the surrounding countryside. Around 1890 the gap in life expectancy at birth between the city of Brussels (35.7 years) and the nearby rural province of Walloon Brabant (48.2 years) was 12.5 years (Eggerickx, 2014a). This urban excess mortality, which was all over Belgium at that time and increased with city size, was mainly seen in children under 5 years old and adults over 30, especially men (Eggerickx, Debuisson, 1990; Van Rossem, 2018). T. Van Rossem showed that in the case of Brussels, the main cause of death among very young children was enteritis, while older children were badly affected by respiratory diseases and adult men by pulmonary tuberculosis (Van Rossem, 2018).

To our knowledge no study has been able to determine whether there was an overall disappearance of urban excess mortality over the twentieth century. In 1920 it still prevailed, for example, in Brussels, where life expectancy at birth was 44.4 years compared to 56.2 years for Walloon Brabant. Nevertheless, it seems that urban and rural mortality began to converge after the First World War, thanks in particular to the reduction in infant mortality (Eggerickx et al., 2012). Today, the most urbanized communities are no longer necessarily those with the highest mortality rates (Eggerickx, Sanderson, 2010; Grimmeau et al., 2015). Still, large cities - in both Flanders and Wallonia - continue to have a life expectancy deficit compared to their respective regional averages, and this deficit has increased over the past 20 years (Eggerickx et al., 2018a). The former Walloon industrial basin, the drivers of the country's urbanization in the nineteenth century and in the grip of a persistent social, economic and urban crisis since the onset of deindustrialization since the 1960s, are still characterized today by a very clear excess mortality relative to other living environments (Eggerickx, 2001; Eggerickx, Sanderson, 2010).

In Wallonia, the extensive peri-urban area of Walloon Brabant, located south of the Brussels conurbation, enjoys considerably higher life expec- 
tancy compared to the regional average and similar to the Flemish communes (Figures 12 and 13). Moreover, all the peri-urban communes around the conurbations of Antwerp, Ghent, Charleroi, Namur, and Liège show a relative undermortality ${ }^{21}$, as do the more rural communes in the south of the province of Luxembourg (in the country's extreme south) due to the peri-urbanization of the city of Luxembourg. All these communes over the past few decades have been a magnet for migrants - especially wealthy households with adults aged 30-49 years and their children - who are increasingly socially selected under ever-increasing land and property pressure (Eggerickx, Sanderson, 2019).

FIGURE 13 Life expectancy at birth of the total population (for both sexes)

for Belgium's communes in 2011-2015

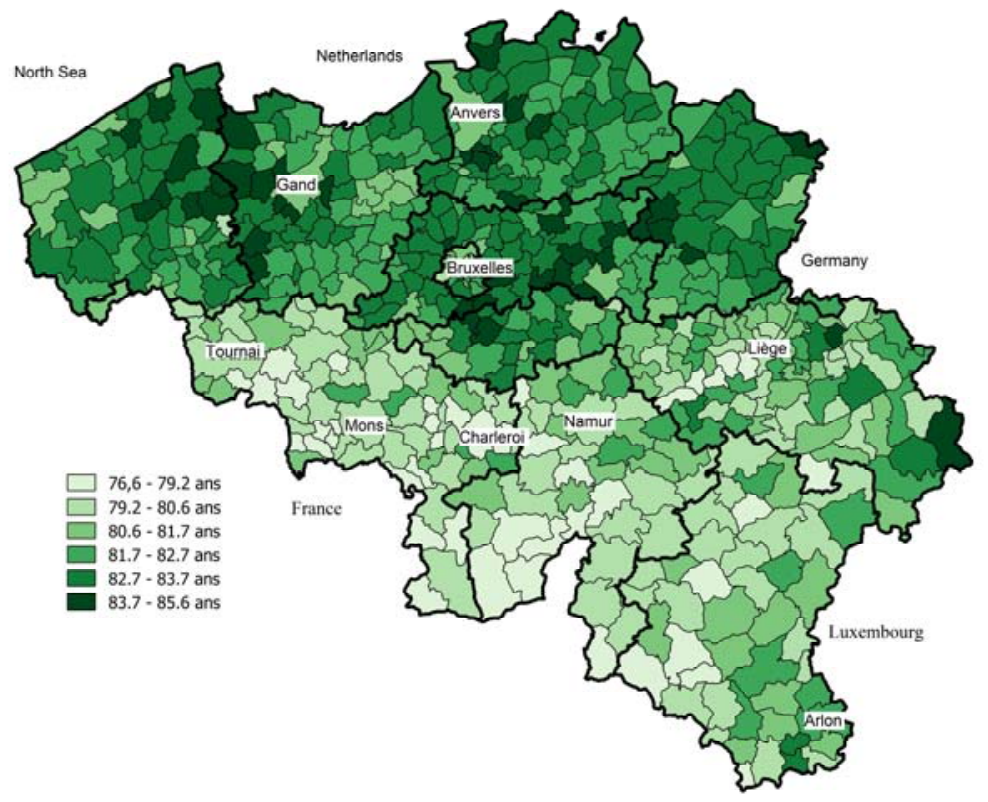

Source: National Register; authors' calculations.

The extent of social inequalities in mortality within regions and subregions, like the growth in spatial inequalities in mortality over recent decades, raises questions about changes in the sociodemographic composition of migrants and by extension the role of migration (Ghosn et al., 2012). In any study of differential demographic behaviours conducted at

21. In terms of their regional average and their conurbation. 
a fine spatial scale, it is necessary to take into consideration the effects of migration and the sociodemographic selectivity of migrants (Norman et al., 2005; Connolly, O'Reilly, 2007). Today as in the past, subregional spaces and residential environments (urban, periurban, rural, etc.) are strongly structured by migration. On the one hand, internal and international migration are the main components of population movement and renewal at fine spatial scales. On the other hand, migrants differ from non-migrants in a number of characteristics - age, sex, family situation, educational level, income, etc. - and can thus influence the demographic and socioeconomic composition of populations at point of origin and point of arrival, and thus their health and mortality profile. In addition, several studies - in contexts both older (Oris, Alter, 2001) and recent (Deboosere, Gadeyne, 2002; Norman et al., 2005; Connolly, O'Reilly, 2007; Brown, Leyland, 2010) - have shown that migrants are on average in better health and can thus affect mortality levels positively in receiving areas and negatively in sending areas. Growing spatial inequalities in mortality can thus be partially explained by the selective effect of migration.

\section{Persistent spatial differences in mortality for identical social groups}

As noted above, socioeconomic characteristics largely account for spatial disparities in mortality. Nonetheless, after controlling for socioeconomic variables, disparities remain at the regional and subregional scales. Thus, the gap between Flanders and Wallonia persists at the same educational level (Deboosere, Gadeyne, 2002). This conclusion was confirmed in a more recent study on premature mortality (24-64 years) among the Belgian-born population in the 2000s (Renard et al., 2017), as well as by Rican et al. (2003) in a study on French departments.

What of the social groups defined above? If differences in mortality are solely the result of the statistical weight of different social groups within each region (effect of socioeconomic composition) then the life expectancy at birth of a given social group should be identical in Brussels, Flanders, and Wallonia ${ }^{22}$. However, within the same social group, regional differences in mortality remain (Table 9). In 2011-2015, for the underprivileged social group, there is a gap of 3.4 years in life expectancy at birth

22. It is important to remember that the social groups are those identified at the country scale and that quartiles have thus not been redefined at the level of each territory (regions, districts), which would invalidate spatial comparisons. In other words, the weight of social groups varies according to territory. 
between Brussels and Wallonia. For the privileged social group, the difference is 1.9 years for men between Flanders and Wallonia. In general, for a social group, the higher its position in the social «hierarchy», the less significant the interregional differences. Finally, between 1992-1996 and 2011-2015, for equal social groups, regional differences in mortality grew: between Flanders and Wallonia, for underprivileged men there was a difference in life expectancy of 3 years in 1992-1996 and 3.4 years 20 years later; for privileged men the differential in life expectancy increased from 1.4 to 1.9 years between the two periods. These trends also apply for women, even if the gaps, for each social group, are less pronounced.

TABLE 9 Changes in life expectancy at birth (by year) according to social group and sex in Belgium's three regions

\begin{tabular}{|c|c|c|c|c|c|c|c|c|}
\hline \multirow{2}{*}{ Social Groups } & \multicolumn{4}{|c|}{ Men } & \multicolumn{4}{|c|}{ Women } \\
\hline & Belgium & Brussels & Flanders & Wallonia & Belgium & Brussels & Flanders & Wallonia \\
\hline \multicolumn{9}{|l|}{$1992-1996$} \\
\hline Underprivileged (5\%) & 65.6 & 68.1 & 66.1 & 63.9 & 75.3 & 76.9 & 75.5 & 74.3 \\
\hline Underprivileged (25\%) & 69.6 & 70.4 & 70.6 & 67.6 & 78.3 & 78.6 & 78.8 & 77.2 \\
\hline Mid-low & 73.5 & 72.6 & 74.6 & 71.9 & 81.1 & 80.5 & 81.6 & 80.3 \\
\hline Mid-high & 75.4 & 74.8 & 76.1 & 74.3 & 82.2 & 81.9 & 82.6 & 81.6 \\
\hline Privileged & 78.0 & 78.1 & 78.4 & 77.0 & 83.1 & 83.4 & 83.5 & 82.3 \\
\hline Total & 73.3 & 73.1 & 74.3 & 71.7 & 80.1 & 80.0 & 80.5 & 79.3 \\
\hline $\begin{array}{l}\text { Difference Privileged- } \\
\text { Underprivileged }\end{array}$ & 8.4 & 7.7 & 7.8 & 9.4 & 4.8 & 4.8 & 4.7 & 5.1 \\
\hline \multicolumn{9}{|l|}{ 2011-2015 } \\
\hline Underprivileged (5\%) & 70.2 & 73.1 & 71.0 & 68.4 & 76.6 & 78.1 & 76.6 & 75.6 \\
\hline Underprivileged (25\%) & 73.9 & 75.2 & 75.0 & 71.7 & 80.4 & 80.8 & 81.1 & 78.9 \\
\hline Mid-low & 78.2 & 77.6 & 79.1 & 76.5 & 84.1 & 83.6 & 84.8 & 82.7 \\
\hline Mid-high & 79.9 & 79.7 & 80.7 & 78.5 & 84.8 & 84.3 & 85.4 & 83.9 \\
\hline Privileged & 83.0 & 82.4 & 83.8 & 81.9 & 87.0 & 86.6 & 87.7 & 86.1 \\
\hline Total & 78.1 & 77.9 & 79.1 & 76.2 & 83.1 & 82.8 & 83.8 & 81.8 \\
\hline $\begin{array}{c}\text { Difference Privileged- } \\
\text { Underprivileged }\end{array}$ & 9.1 & 7.3 & 8.8 & 10.1 & 6.6 & 5.8 & 6.6 & 7.3 \\
\hline
\end{tabular}

Sources: national census data; authors' calculations.

At the district level the contrasts become more obvious. Among underprivileged men there is a gap of more than 7 years while for privileged men it is 4.5 years. For women the differences fluctuate between 4.4 and 5 years depending on social group. The standard deviation is generally greater for underprivileged than for privileged social groups, reflecting greater homogeneousness in term of mortality among the latter (Table 10). 
TABLE 10 Selected indexes for differences in mortality according to social group at the district level in 2011-2015

\begin{tabular}{|c|c|c|c|c|c|c|c|c|}
\hline \multirow[b]{2}{*}{ Social Groups } & \multicolumn{4}{|c|}{ Men } & \multicolumn{4}{|c|}{ Women } \\
\hline & $\begin{array}{l}\text { Underprivi- } \\
\text { leged }\end{array}$ & $\begin{array}{l}\text { Mid- } \\
\text { low }\end{array}$ & $\begin{array}{l}\text { Mid- } \\
\text { high }\end{array}$ & $\begin{array}{l}\text { Privi- } \\
\text { leged }\end{array}$ & $\begin{array}{l}\text { Underprivi- } \\
\text { leged }\end{array}$ & $\begin{array}{l}\text { Mid- } \\
\text { low }\end{array}$ & $\begin{array}{l}\text { Mid- } \\
\text { high }\end{array}$ & $\begin{array}{l}\text { Privi- } \\
\text { leged }\end{array}$ \\
\hline Minimium & 69.6 & 75.1 & 76.6 & 80.1 & 76.6 & 81.2 & 81.8 & 84.9 \\
\hline Maximum & 76.8 & 80.3 & 82.5 & 84.6 & 81.5 & 85.8 & 86.2 & 89.7 \\
\hline Difference & 7.2 & 5.2 & 5.9 & 4.5 & 5.0 & 4.6 & 4.4 & 4.8 \\
\hline Average & 73.9 & 78.1 & 79.9 & 83.0 & 80.4 & 84.0 & 84.8 & 87.0 \\
\hline Standard Deviation & 1.98 & 1.56 & 1.43 & 1.37 & 1.44 & 1.30 & 1.09 & 1.14 \\
\hline
\end{tabular}

Sources: 2011 national census data; authors' calculations.

In districts where life expectancy is high for the privileged social group, it is also higher for the underprivileged group (Figure 14). Taking the example of the Walloon districts of Nivelles and Mons' ${ }^{23}$. For Nivelles, located within Brussels's wealthy periurban area, male life expectancy for privileged and underprivileged social classes are, for 2011-2015, 83.4 and 73.4 years respectively, much higher than the averages for Wallonia (71.7 and 81.9 years respectively). For Mons, formerly the industrial centre of the Borinage area and today socially disenfranchised, these two social groups ( 70.3 and 80.6 years respectively) both sit below the regional averages. In other words, the composition of the social environment (i.e., the presence in the same territory of different social groups) would have a positive effect on health and mortality where the privileged groups are better represented and a negative effect where they are in the minority.

This means that the socioeconomic composition of district populations is insufficient to explain mortality differences. Other factors are at play - e.g., environmental, cultural, behavioural - and affect the mortality of all groups in the same way. As Rican et al. (2003, p. 145) have noted for France, «there are surely ways of drinking and eating, and lifestyle factors more generally, that are associated with regional belonging and not just individual social status». This statement most likely also applies, as a whole or in part, to Belgian districts. An additional factor is high spatial differentiation in the availability and quality of health services (Bourguignon et al., 2017).

23. In 2011, the privileged social group accounted for $33 \%$ of the population of the district of Nivelles and $21 \%$ for Mons, while for the underprivileged group it was $15 \%$ and $31 \%$ respectively. In 2015 the average declared income was 36'648 euros for Nivelles and 27'222 euros for Mons. 
Figure 14 Male life expectancy at birth by district and social group (2011-2015) Underprivileged social group

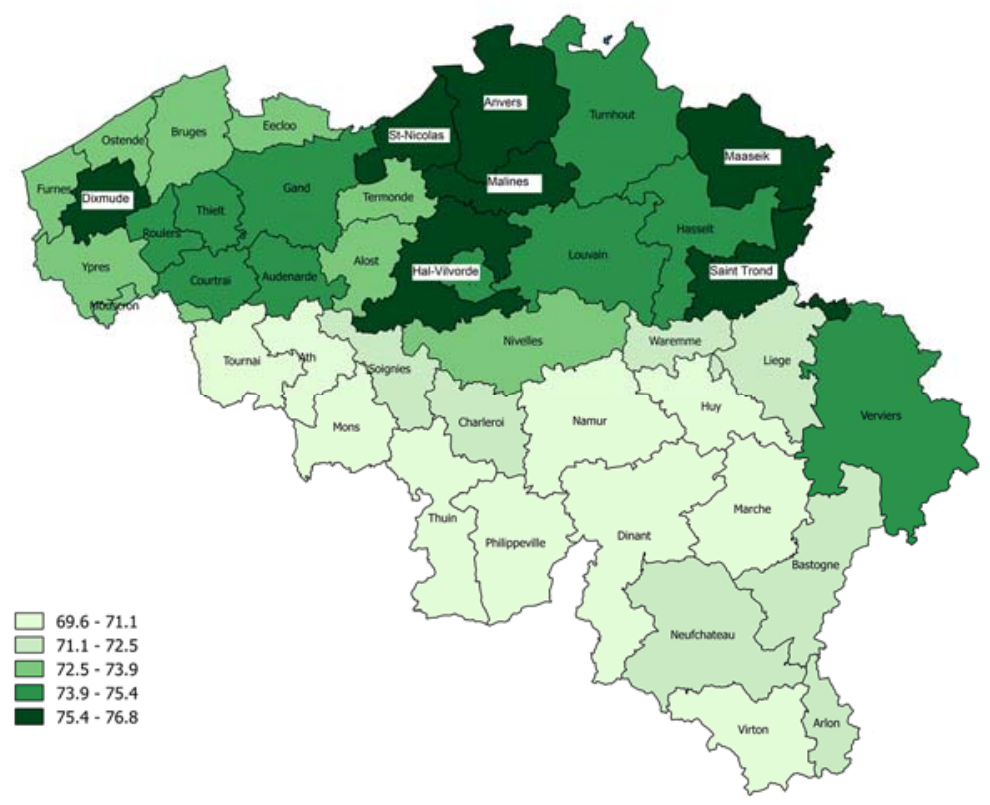

Privileged social group

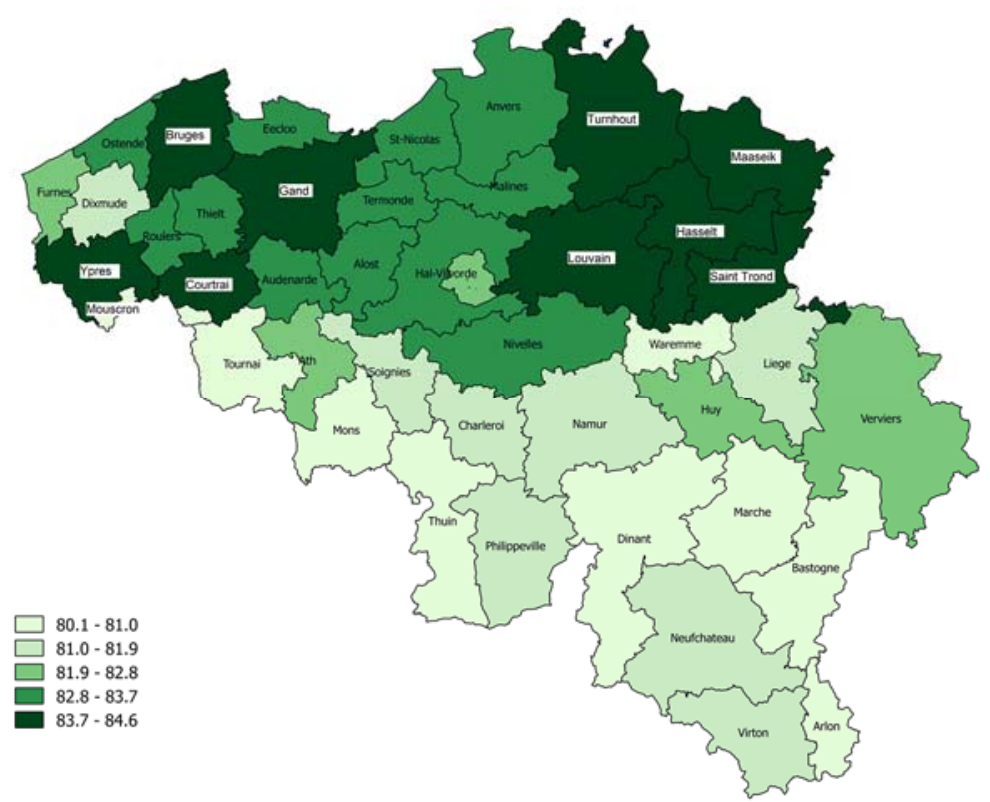

Source: national census data; authors' calculations. 
Nonetheless, it is certain that the district scale, which is still too wide and includes «environments» that are highly disparate, is not the most appropriate for measuring the respective effects of these factors. Only through a more local approach could things be taken further, so long as the necessary data is available and an aggregation by commune type is done in order ensure a high enough number of deaths for each social group.

Another of the limitations of these spatial and transversal approaches must also be pointed out, and that is that an individual's place of residence is identified at the time of their death - and it is not necessarily the place where the individual was most exposed to risk factors over the course of their life. It is thus also important to take into consideration lengths of residence and migration paths, data that is rarely available and used in transversal and aggregate studies (Noin, 1990; Norman et al., 2005).

\section{Conclusions}

In Belgium, life expectancy is now twice what it was 170 years ago due to improvements in public and private hygiene, nutrition, medical procedures, and the organization of health services. The average lifespan is now over 80 years. At the same time, as in other Western countries, differences and inequalities persist and sometimes even intensify. This is the case when mortality is analyzed by genre, age, social environment, region, and residential area. The goal of this article has been to examine the evolution of variations in mortality according to these variables in Belgium within the theoretical framework of the health transition.

Today women live on average 4.5 years longer than men. From the midnineteenth century to the mid-1980s, differences in life expectancy between sexes have grown. On the one hand this is because of factors having a positive impact on women's survival, such as improvements in pregnancy monitoring and childbirthing conditions and fewer pregnancies, and on the other hand because of factors unfavourable for men's mortality, such as increased exposure to workplace accidents, road accidents, smoking and alcoholism. Since 1985 the gaps have shrunk, particularly due to a large decrease in cardiovascular mortality among men, boosted by their adoption of behaviours conducive to better health (such as prevention and follow-up treatment). 
Improvements in life expectancy at birth over time go along with changes in the distribution of deaths by age. Until the start of the twentieth century children under five years old accounted for nearly $30 \%$ of deaths compared to less than $0.5 \%$ today. Nearly two-thirds of those who die today are more than 80 years old, compared to $10 \%$ in the nineteenth century. The age groups have not all had the same level of impact, nor at the same time, on rising life expectancy.

The doubling of life expectancy at birth is first the result of a near-eradication of child mortality, mainly due to progress in the fight against infectious diseases, and then a massive decline in cardiovascular mortality, which allowed for the delaying of death for many older people. In recent decades, older people have been the main drivers of improved life expectancy at birth.

It has been shown, based on a multidimensional indicator that combines educational level, occupational category, and housing characteristics, that social inequalities in death are significant in Belgium and that they have been increasing for both women and men since at least the 1990s. In relative terms, gaps between social groups are especially wide between 25 and 50 years, but because at these ages the risk of dying is inherently low, they have little impact on differences in life expectancy, unlike the social mortality differential beyond age 65 .

Similarly, these older people have a far greater effect on improvements in life expectancy for the privileged social group than for the underprivileged, reflecting the latter's delay in the health transition and especially in the fight against cardiovascular diseases. In general, social inequalities in mortality and their variation along the social continuum are observed for each of the major causes of death, but more particularly for diseases of the respiratory and circulatory systems.

Finally, spatial disparities in mortality, at the regional, district, and place of residence, linger and indeed have been worsening for a least a quarter century. The spatial pattern of mortality for the underprivileged social group resembles those of the privileged and intermediate social groups. Within the same social group spatial disparities endure. This indicates that beyond the socioeconomic composition of regions and districts, other factors - environmental, cultural, and behavioural - are involved and affect mortality of all social groups in the same way. 


\section{References}

Annuaire statistique de la Belgique, Tome 1, 1870.

Antonovsky A. (1967), "Social Class, Life Expectancy and Overall Mortality», The Milbank Memorial Fund Quarterly, 45 (2), Part. 1, pp. 31-73, https://doi.org/10. 2307/3348839.

Adveev A., Eremenko T., Festy P., Gaymu J., Le Bouteillec N., Spinger S. (2011), «Populations et tendances démographiques des pays européens (1980-2010)", PopulationF, 66 (1), pp. 9-133, https://doi.org/10.3917/popu.1101.0009.

BARBIERI M. (2013), «La mortalité départementale en France», Population, 3 (68), pp. 433-479, https://doi.org/10.3917/popu.1303.0433.

Bılııet A. (2010), "Les inégalités sociales de santé en Wallonie», L'observatoire, 65, pp. 20-24.

Bourguignon M., EggerickX T., SANDERSON J.-P. (2017), «Quels territoires de santé gérontologique pour repenser l'adéquation entre offre et besoins d'aides en Wallonie ?», Revue francophone sur la santé et les territoires, pp. 1-23.

Brown D., LeYland A. H. (2010), «Scottish Mortality Rates 2000-2002 by Deprivation and Small Area Population Mobility", Social Science \& Medicine, 71, pp. 1'951-1'957, https://doi.org/10.1016/j.socscimed.2010.09.015.

Самвois E., Jusot F. (2007), «Ampleur, tendance et causes des inégalités sociales de santé et de mortalité en Europe : une revue des études comparatives», Bulletin épidémiologique hebdomadaire, 2-3, pp. 10-14.

CoBURN D. (2004), «Beyond the Income Inequality Hypothesis: Class, Neo-Liberalism and Health Inequalities», Social Science \& Medicine, 58, pp. 41-56, https://doi.org/ 10.1016/S0277-9536(03)00159-X.

Connolly S., O'Reilly D. (2007), «The Contribution of Migration to Changes in the Distribution of Health over Time: Five-Year Follow-Up Study in Northern Ireland», Social Science \& Medicine, 65, pp. 1'004-1'011, https://doi.org/10.1016/j.socscimed. 2007.04.035.

Deboosere P., Gadeyne S. (2002), «Can Regional Patterns of Mortality in Belgium Be Explained by Individual Socio-Economics Characteristics?», Reflets et Perspectives, XLI (4), pp. 87-103, https://doi.org/10.3917/rpve.414.0087.

Deboosere P., Gadeyne S., Van Oyen H. (2008), «The 1991-2004 Evolution in Life Expectancy by Educational Level in Belgium Based on Linked Census and Population Register Data», European Journal of Population, 25 (2), pp. 175-206, https://doi.org/ 10.1007/s10680-008-9167-5.

Devos I. (1996), «La régionalisation de la surmortalité des jeunes filles en Belgique entre 1890 et 1910", Annales de Démographie Historique, pp. 300-333, https://doi. org/10.3406/adh.1996.1928. 
Devos I. (2010), "Drie eeuwen sterfte in België, 18de-20ste eeuw», Histoire de la population de la Belgique et de ses territoires, Chaire Quetelet 2005, Centre de recherche en démographie, UCLouvain, Louvain-la-Neuve, pp. 591-612.

DuChene J., Thiltgès E. (1993), «La mortalité des plus de 15 ans en Belgique : les disparités régionales en 1985-1987», Espace, Populations, Sociétés, 1, pp.61-74, https://doi.org/10.3406/espos.1993.1556.

EgGERICKX T. (2001), "La mortalité dans le bassin industriel de Charleroi aux 19ème et 20ème siècles : un handicap socio-démographique récurrent», Espace, Populations, Sociétés, 3, pp. 351-368, https://doi.org/10.3406/espos.2001.2003.

EGGERICKX T. (2014a) "Transition démographique et banlieues en Belgique», Annales de Démographie Historique, 2, pp. 51-80, https://doi.org/10.3917/adh.126.0051.

EggeRICKX T. (2014b), "L'impact démographique de la Première Guerre mondiale. Tendances générales et diversités spatiales», H. HASQUIN (ed), La bataille de Charleroi. 100 ans après, Bruxelles, Académie Royale de Belgique, pp. 105-135.

Eggerickx T., Debuisson M. (1990), "La surmortalité urbaine : le cas de la Wallonie et de Bruxelles à la fin du 19ème siècle (1889-1892)", Annales de Démographie Historique, 1, pp. 23-41, https://doi.org/10.3406/adh.1990.1756.

Eggerickx T., Debuisson M., SANDerson J.-P. (2012), «La mortalité des jeunes enfants de moins d'un an en Belgique, de 1840 à 1925. Une approche spatiale», Annales de Démographie Historique, 1, pp. 25-61, https://doi.org/10.3917/adh.123.0025.

EgGerickX T., LÉGER J.-F., SANDERSON J.-P., VANDESCHRICK C. (2018a), «Inégalités sociales et spatiales de mortalité dans les pays occidentaux. Les exemples de la France et de la Belgique», Espace, Populations, Sociétés, [En ligne], 1-2, https://doi.org/10.4000/eps.7800.

EggerickX T., Poulain M. (1991), «Le choléra, cet autre fléau social du 19ème siècle. L'épidémie de 1866 en Belgique et son exacerbation des inégalités face à la mort», Historiens et populations. Liber Amicorum Étienne Hélin, Louvain-la-Neuve, pp. 203218.

EgGerickX T., SANDERSON J.-P. (2010), «Les inégalités spatiales de mortalité en Belgique : 1980-2005», Démographie et Santé, Cudep, Bordeaux, pp. 145-161.

EGgERICKX T., SANDERSON J.-P. (2019), «Migrations résidentielles, ségrégation sociale et vieillissement démographique : le cas de l'espace périurbain bruxellois», Espace, Populations, Sociétés, https://doi.org/10.4000/eps.8904.

EgGerickX T., SANDERSON J.-P., VANDESChrick C. (2018b), «Les inégalités sociales et spatiales de mortalité en Belgique : 1991-2016», Espace, Populations, Sociétés, [En ligne], 1-2, https://doi.org/10.4000/eps.7416.

Eggerickx T., TAButin D. (1994), "La surmortalité des filles en Belgique vers 1890 », Population, 3, pp. 657-684, https://doi.org/10.2307/1533962.

Fallon V. (1942), Famille et Population, Tournai. 
GADEYNE S. (2006), The Ultimate Inequality: Socio-Economic Differences in All-Causes and Cause-Specific Mortality in Belgium in the First part of the 1990s, NIDI CBGS Publications, 39, Bruxelles, $260 \mathrm{p}$.

Galobardes B., LyNCH J., SMith G. D. (2007), «Measuring Socioeconomic Position in Health Research», British Medical Bulletin, 81-82 (1), pp. 21-37, https://doi.org/10. 1093/bmb/ldm001.

Ghosn W., Kassié D., Jougla E., Salem G., Rey G., Rican S. (2012), «Trends in Geographic Mortality Inequalities and their Associations with Population Changes in France, 1975-2006», European Journal of Public Health, 23 (5), pp. 834-840, https://doi.org/ 10.1093/eurpub/cks078.

Grimmeau J.-P., Deboosere P., Eggerickx T., Gadeyne S., Hermia J.-P., Marissal P., Romainville A., Van Hecke E., Willaert D. (2015), Atlas de Belgique, 6, Population, Gand, 104 p.

Grimmeau J.-P., Romainville A., Beyts N. (2010), "Évolution de la géographie de la mortalité en Belgique, 1840-2002», T. EGGERICKX, J.-P. SANDERSON (eds), Histoire de la population de la Belgique et de ses territoires. Chaire Quetelet 2005, Presses Universitaires de Louvain, pp. 613-626.

HerJean P. (2006), "L'approche multiniveau de la santé», Cahiers de géographie du Québec, 50 (141), pp. 347-355, https://doi.org/10.7202/014875ar.

Ho J., Hendi A. (2018), «Recent Trends in Life Expectancy Across High Income Countries: Retrospective Observational Study», BMJ (British Medical Journal), 15 Aug., 362 (k2562), 14 p., https://doi.org/10.1136/bmj.k2562.

Jasilionis D., Shkolnikov V., Andreev E., Jdanov D., Meslé F., Vallin J. (2014), «L'avantgarde en matière d'espérance de vie montre-t-elle la voie au reste de la population ?», Population, 69 (4), pp. 589-615, https://doi.org/10.3917/popu.1404.0589.

Jusot F. (2003), Revenu et Mortalité : Analyse économique des inégalités sociales de santé en France, Thèse de doctorat de l'EHESS.

KUBORN H. (1897), Aperçu historique sur I'hygiène publique en Belgique depuis 1830, Bruxelles.

KUnSt. A. E., MACKEnBACH J. P. (1994), «International Variation in Size of Mortality Differences Associated with Occupational Status», International Journal of Epidemiology, 23 (4), pp. 742-750, https://doi.org/10.1093/ije/23.4.742.

Lagasse R., Humblet P., Lenaerts A., Godin I., Moens G. (1990), «Health and Social Inequities in Belgium», Social Science \& Medicine, 31 (3), pp. 237-248, https://doi.org/ 10.1016/0277-9536(90)90270-3.

Link B. G., Phelan J. C. (1995), "Social Conditions as Fundamental Causes of Disease», Journal of Health and Social Behaviour, Extra Issue, pp. 80-94, https://doi.org/10. 2307/2626958. 
MACINTYRE S. (1997), "The Black Report and Beyond what Are the Issues?», Social Science and Medicine, 44 (6), pp. 723-745, https://doi.org/10.1016/S0277-9536(96) 00183-9.

MAckenbaCH J. P. (2012), «The Persistence of Health Inequalities in Modern Welfare States: The Explanation of a Paradox», Social Science \& Medicine, 75, pp. 761-769, https://doi.org/10.1016/j.socscimed.2012.02.031.

Mackenbach J. P., Stribu I., Roskam A.-J., Schaap M., Menvielle G., Leinsalu M., Kunst A. (2008), "Socioeconomic Inequalities in Health in 22 European Countries», The New England Journal of Medicine, June 5, pp. 2'468-2'481.

Masuy-Stroobant G. (1983), Les déterminants de la mortalité infantile. Belgique d'hier et d'aujourd'hui, Louvain-la-Neuve, $540 \mathrm{p}$.

MasuY-Stroobant G. (2010), "Mères et nourrissons. Aux origines de la protection maternelle et infantile en Belgique», T. EGGERICKX, J.-P. SANDERSON (eds), Histoire de la population de la Belgique et de ses territoires. Chaire Quetelet 2005, Louvain-laNeuve, Presses Universitaires de Louvain, pp. 627-656.

MEsté F. (2004), «Écart d'espérance de vie entre les sexes : les raisons du recul de l'avantage féminin", Revue d'Épidémiologie et de Santé Publique, 52, (4), pp. 333352, https://doi.org/10.1016/S0398-7620(04)99063-3.

Meslé F., Valuin J. (2002), "La transition sanitaire : tendances et perspectives», G. CASELLI, J. VALLIN, G. WUNSCH (eds), Démographie : analyse et synthèse. III. Les déterminants de la mortalité, Éditions de l'INED, Paris, pp. 439-461.

Mızrahı A., Mızrahı A. (2002), "Inégalités sociales face au vieillissement et à la mort», Gérontologie et Société 2, 25 (101), pp. 63-83, https://doi.org/10.3917/gs.101.0063.

Noin D. (1990), «L'étude géographique de la mortalité : bilan et problèmes», Espace, Populations, Sociétés, 3, pp. 367-376, https://doi.org/10.3406/espos.1990.1412.

Norman P., Boyle P., ReEs P. (2005), «Selective Migration, Health and Deprivation: A Longitudinal Analysis», Social Science \& Medicine, 60, pp. 2'755-2'771, https://doi. org/10.1016/j.socscimed.2004.11.008.

OMran A. R. (1971), «The Epidemiologic Transition: A Theory of the Epidemiology of Population Change», The Milbank Memorial Fund Quarterly, 49 (4), pp. 509-538, https://doi.org/10.2307/3349375.

OrIS M., Alter G. (2001), "The Family and Mortality: A Case Study from Rural Belgium», Annales de Démographie Historique, 101 (1), pp. 1-31, https://doi.org/10. 3917/adh.101.0010.

ORIS M., LeRCH M. (2009), «La transition ultime. Longévité et mortalité aux grands âges dans le bassin lémanique», M. ORIS et al. (eds), Transitions dans les parcours de vie et construction des inégalités, Lausanne, pp. 407-432. 
Oris M., Ramiro Farinas D. (2016), «New Approaches to Death in Cities during the Health Transition: An Introduction», D. RAMLIRO FARINAS, M. ORIS (eds), New Approaches to Death in Cities During the Health Transition, International Studies in Population, IUSSP, Springer, pp. 1-16, https://doi.org/10.1007/978-3-319-43002-7_ 1.

PIson G. (2015), "Tous les pays du monde», Population \& Sociétés, INED, 8 p., https://doi.org/10.3917/popsoc.525.0001.

Poulain M., Masuy-Stroobant G. (1983), «La variation spatiale et temporelle du déclin de la mortalité infantile dans nos régions», Espace, Population et Sociétés, (1), pp. 63-73, https://doi.org/10.3406/espos.1983.905.

Poulain M., Tabutin D. (1977), "Mortalité aux jeunes âges en Belgique de 1840 à 1970», Population et Famille, 42, pp. 49-86.

Poulain M., TABUtin D. (1981), «La surmortalité des petites filles en Belgique au 19ème et au début du 20ème siècle», Annales de Démographie Historique, pp. 105118, https://doi.org/10.3406/adh.1981.1491.

Pressat R. (1985), «Contribution des écarts de mortalité par âge à la différence des vies moyennes», Population, 4-5, pp. 766-770, https://doi.org/10.2307/1532986.

Quetelet A. (1869), Physique sociale ou essai sur le développement des facultés de I'homme, Réédition annotée par E. VILQUIN et J.-P. SANDERSON, Académie Royale de Belgique, Classe des Lettres, Gilly, 1997, $701 \mathrm{p}$.

Renard F., Devleesschaumer B., Gadeyne S., Tafforeau J., Deboosere P. (2017a), «Educational Inequalities in Premature Mortality by Region in the Belgian Population in the 2000s", Archives of Public Health, 75 (44), pp.1-16, https://doi.org/10.1186/ s13690-017-0212-x.

Renard F., Devleesschauwer B., Van Oyen H., Gadeyne S., Deboosere P. (2019), «Evolution of Educational Inequalities in Life and Health Expectancies at 25 Years in Belgium between 2001 and 2011: A Census-Based Study», Archives of Public Health, 77 (6), https://doi.org/10.1186/s13690-019-0330-8.

Renard F., Gadeyne S., Devleesschauwer B., Tafforeau J., Deboosere P. (2017b), "Trends in Educational Inequalities in Premature Mortality in Belgium between the 1990s and the 2000s: The Contribution of Specific Causes of Death», Journal Epidemiol Community Health, 71 (4), pp. 371-380, https://doi.org/10.1136/jech-2016208370.

Rican S., Jougla E., SALEM G. (2003), «Inégalités socio-spatiales de mortalité en France», $B E H, 30-31$, pp. 142-145.

Rollet C., Bourdelais P. (1993), «Infant Mortality in France - 1750-1950 - Evaluation and Perspectives", C. CORSINI, P. VIAZZO (eds), The Decline of Infant Mortality in Europe, 1800-1950, Four National Case Studies, Instituto degli Innocenti di Firenze, Florence, Unicef, pp. 51-70. 
TAButin D. (1978), «La surmortalité feminine en Europe avant 1940», Population, 1, pp. 121-148, https://doi.org/10.2307/1531720.

TAButin D., Willems M. (1998), «Differential Mortality by Sex from Birth to Adolescence: The Historical Experience of the West (1750-1930)», Too Young to Die: Genes or Gender?, New York, United Nations Population Division.

Valkonen T. (2002), "Les inégalités sociales devant la mort», G. CASELLI, J. VALLIN, G. WUNSCH (eds), Démographie : analyse et synthèse. III. Les déterminants de la mortalité, Éditions de l'INED, Paris, pp. 351-372.

VAluin J. (2002), "Mortalité, sexe et genre», G. CASELLI, J. VALLIN, G. WUNSCH (eds), Démographie : analyse et synthèse. III. Les déterminants de la mortalité, Éditions de I'INED, Paris, pp. 319-350.

VALLIN J., MesLÉ F. (2013), «De la transition épidémiologique à la transition sanitaire : l'improbable convergence générale», D. TABUTIN, B. MASQUELIER (eds), Ralentissements, résistances et ruptures dans les transitions démographiques. Actes de la Chaire Quetelet 2010, Louvain-la-Neuve, Presses Universitaires de Louvain, pp. 257-290.

VAN Houte-Mınet M., WUNSCH G. (1978), «La mortalité masculine aux âges adultes, un essai d'analyse régionale», Population et Famille, 104, pp. 3-42.

Van Oyen H., Deboosere P., Lorant V., Charafeddine R. (2010), Les inégalités sociales de santé en Belgique, Société et Avenir, Politique Scientifique Fédérale, Academia Press, Gent, $200 \mathrm{p}$.

VAN Rossem T. (2018), Bruxelles ma belle, Bruxelles mortelle. An investigation into excess mortality in Brussels at the turn of the twentieth century, VUBPRESS, Brussels, $582 \mathrm{p}$.

Willems S., Van de Geuchte I., Alaluf V., Impens J., Van Nespen I., Maulet N., Roland M., De Maeseneer J. (2007), «Problématique des inégalités socio-économiques de santé en Belgique», Santée conjuguée, avril, 40, pp. 25-34.

WINTER J. M. (1988), "Some Paradoxes of the First World War», R. WALL, J. WINTER (eds), The Upheaval of War: Family, Work and Welfare in Europe, 1914-1918, Cambridge University Press, Cambridge, pp. 9-42. 